\title{
Inflation Risk Premia, Yield Volatility and Macro Factors
}

\author{
ANDREA BERARDI and ALBERTO PLAZZI*
}

\begin{abstract}
We incorporate a latent stochastic volatility factor and macroeconomic expectations in an affine model for the term structure of nominal and real rates. We estimate the model over 1999-2016 on U.S. data for nominal and TIPS yields, the realized and implied volatility of T-bonds and survey forecasts of GDP growth and inflation. We find relatively stable inflation risk premia averaging at $40 \mathrm{bps}$ at the long-end, and which are strongly related to the volatility factor and conditional mean of output growth. We also document real risk premia that turn negative in the post-crisis period, and a non-negligible variance risk premium.
\end{abstract}

Keywords: Term structure, Inflation risk premia, TIPS, Yield volatility, Macro factors

JEL classification: G12, E43, E44, C58

*Berardi: Università Ca' Foscari Venezia, Dipartimento di Economia, Fondamenta San Giobbe 873, 30121, Venezia, Italy, Email: andrea.berardi@unive.it. Plazzi: Università della Svizzera italiana and Swiss Finance Institute, Institute of Finance, Via Buffi 13, 6904, Lugano, Switzerland, Email: alberto.plazzi@usi.ch, Phone: +4158666 4677. 


\section{Introduction}

Analyzing the dynamics of real interest rates, inflation expectations and inflation risk premia is relevant for a wide array of financial decisions. Central banks, for example, may use the information from inflation-indexed bond prices to infer inflation expectations and determine the conduct of monetary policy. Index-linked bonds are also particularly suitable financial instruments for the investment strategies of institutional investors, such as pension funds and insurance companies.

Observing the dynamics of bond prices denominated in both nominal and real terms enables the nominal yield of any maturity to be separated into its individual components, i.e. the real interest rate, the expected inflation rate and the inflation risk premium. The latter arises from the fact that investors holding nominal bonds are exposed to unanticipated changes in future inflation, and therefore command a premium to bear such risk. In principle, the size and sign of the premium depends on the covariance between shocks to consumption and inflation. If this covariance is negative, meaning that consumption tends to be low when inflation is high, then nominal assets bear more risk and investors require a positive premium to hold them. If the covariance is positive, then nominal bonds become a hedging instrument for negative shocks in consumption and the inflation risk premium can be negative.

In the United States, the issuance of inflation-linked bonds (denominated TIPS) has started only in 1997, but the market has since then grown very rapidly. ${ }^{1}$ The empirical evidence on the properties of the U.S. inflation risk premia from the TIPS market is, however, rather mixed. A strand of the literature documents medium- to long-term inflation risk premia that are mainly positive, with the 10-year premium averaging between 40bps and 60bps (see e.g. Durham (2006), Adrian and Wu (2009), D'Amico et al. (2010), Chen et al. (2010), and Haubrich et al. (2012)). On the other hand, other studies claim that long-term inflation risk premia are, on average, close to zero (see e.g. Christensen et al. (2010), Hordahl and Tristani (2010), and Grishchenko and Huang (2013)). In general, there is agreement about the fact that short-term inflation risk premia should be either very small or negative. Other empirical works analyze the dynamics of inflation risk premia in the U.S. over longer time periods, but in doing so do not make use of data on inflation-

\footnotetext{
${ }^{1}$ At present, the U.K. index-linked gilts market established in 1981 is the major market for inflation-indexed bonds with the longest history of available data. Index-linked gilts currently account for a significant element of the U.K. government securities market. More recently, Japan and some European countries, such as Germany, France, Italy and Sweden, also started to issue this type of bond.
} 
linked bond prices (see, for example, Buraschi and Jiltsov (2005), Ang et al. (2008), Chernov and Mueller (2012), and Ajello et al. (2014)). ${ }^{2}$

In this paper, we contribute to both the modelling and estimation of inflation risk premia. On the former, we develop a novel model where the nominal and real term structures, and their volatilities, are explicitly linked to latent stochastic volatility and economic factors. The existing studies on inflation risk premia either focus on the role of volatility (such as Adrian and Wu (2009) and Haubrich et al. (2012)), or on measures of real economic activity (such as, Hordahl and Tristani (2010)). To the best of our knowledge, no study simultaneously takes into account the joint influence of these two factors on yields and inflation risk premia. We fill this void by casting aggregate stochastic volatility and macroeconomic conditions as captured by the conditional mean of output growth in a parsimonious no-arbitrage affine term structure model. The model delivers endogenous closed-form solutions for the term structures of nominal and real rates, their volatilities, output growth and inflation expectations under the physical probability measure, and inflation and real risk premia.

We relate nominal and real rates to four economic drivers. The instantaneous real rate and inflation expectations naturally derive from the Fisher theorem as key determinants of the real and nominal term structure. Benninga and Protopapadakis (1983) show that under uncertainty the term structure of real and nominal interest rates is related to the short-term real rate, inflation rate, and risk premia due to the variability of money prices and the purchasing power riskiness of nominal bonds.

Our third factor is represented by expected output (real GDP) growth. A number of studies document significant role for macroeconomic variables in explaining the term structure of interest rates (see Ang and Piazzesi (2003) and Diebold et al. (2006)). This role extends over and beyond the standard level, slope, and curvature components of the cross-section of (nominal) yields. Among others, Ludvigson and Ng (2009), Bikbov and Chernov (2010), and Joslin et al. (2014) show that macroeconomic variables help explaining bond risk premia, the level of yields, or both. ${ }^{3}$

\footnotetext{
${ }^{2}$ In these studies, the estimated average 10-year inflation risk premium is positive, but its magnitude varies significantly depending on the data that is used in the estimation and on the inclusion of very different volatility scenarios for yields and inflation, such as the oil shocks of the 1970s, the 1979-82 "Volcker experiment", the Great Moderation after 1984, the internet bubble of the late 1990s, and the "Greenspan conundrum" of the 2000s. Empirical studies on the U.K. (see, among others, Evans (2003) and Joyce et al. (2010)) and the Eurozone (see, for example, Hordahl and Tristani (2010, 2012), Garcia and Werner (2010), and Andersen (2011)) have also produced mixed results about the size and signs of inflation risk premia.

${ }^{3}$ Also related is Chun (2010), who finds that survey expectations about inflation and output growth contain important information for
} 
Finally, we incorporate a fourth stochastic volatility factor that is responsible for time-varying conditional second moment in the other state variables. There is a voluminous literature investigating the relation between yields and volatility (see among others Heston (1993), CollinDufresne et al. (2009), Jacobs and Karoui (2009), and more recently Cieslak and Povala (2016) and Feldhütter et al. (2016)). In the context of affine models, our approach is similar in spirit to Almeida et al. (2011), who use interest rate caps data and show that the inclusion of stochastic volatility improves the fit of bond risk premia. Also closely related is Creal and Wu (2017), who simultaneously model the first and second moments of macro variables and yields and show that stochastic volatility may impact their conditional means. On a similar vein, Bansal and Shaliastovich (2012) develop a long-run risk model where the volatilities of inflation and real growth are treated separately and affect bond risk premia. None of these studies, however, looks at aggregate stochastic volatility with the purpose of understanding inflation risk premia.

In addition, we account for the possibility that TIPS yields (which we use in our empirical analysis) are occasionally inaccurate proxies of real rates due to lack in the liquidity of this market (see Campbell et al. (2009), D'Amico et al. (2010), and Grishchenko and Huang (2013)). We accomplish this by introducing a liquidity factor that enters the pricing of TIPS, but not that of nominal yields.

Our empirical contribution is to fit the model using observable proxies of yields volatility and market expectations about economic activity. To be precise, we estimate the model over the 1999 to 2016 period by maximum likelihood using a Kalman filter algorithm. Our observation equations consist of monthly observations of nominal Treasury yields, TIPS yields, and surveys of professional forecasts (SPF) for GDP growth and inflation. Moreover, we also require the model to fit the term structure of realized volatilities and the implied volatility of the 10-year Treasury-Note future options. Thus, we attempt to match simultaneously the cross-section and time-series properties of both the level of yields (which include risk compensation) and their second moment, and link them to observable macro expectations. The T-note series plays a key role in enhancing our identification of both stochastic volatility and the risk premium parameters. In these respects, our approach is similar to Cieslak and Povala (2016) who document that informative second-moment data (realized 
and implied) improve the precision of the filtering. ${ }^{4}$.

In terms of goodness of fit, we find that the model passes nearly all standard moment specification tests, and delivers reasonable levels for the maximal attainable Sharpe Ratio (see Duffee (2010)). In particular, we cannot reject the null hypothesis of zero differences between the modelimplied and realized first and second moment of nominal yields, TIPS, yield volatilities, and GDP forecasts. As a further validation exercise, we document a similar performance when applying the 1999-2016 model estimates to the 1985-1998 period, for which data on TIPS is not available.

Turning to the model-implied estimates, during the whole sample period the term structure of inflation risk premia is generally positively sloped, with average premia raising from $12 \mathrm{bps}$ at the 2-year to about 44bps at the 10-year maturity. The premia are highest in the pre-crisis period, get closer to zero at the peak of the crisis, and finally revert back to their pre-crisis levels. In terms of level, our 10-year series is in between those reported by Grishchenko and Huang (2013) and Haubrich et al. (2012). However, unlike Haubrich et al. (2012) our short-term inflation risk premia do not plummet into negative territory at the peak of the crisis. In contrast with other studies that feature macro factors (Hordahl and Tristani (2010)) or rely on yield-only approaches (Christensen et al. (2010)), we estimate inflation risk premia that are less volatile and noisy. This result resonates with the evidence in Almeida et al. (2011) that incorporating stochastic volatility in an affine model helps improving the precision with which risk premia are estimated.

In terms of economic significance of the factors, we find that stochastic volatility and (especially) expected output growth are key drivers of inflation risk premia. However, while the effect of the volatility factor increases with maturities, the impact of expected output growth is positive, humpshaped, and economically large both at the short and long end. Together, these two factors explain nearly $35 \%$ of the variance of 10 -year inflation risk premia.

The model also reveals quite rich dynamics for real risk premia. The term structure is positively sloped in the pre-crisis periods, but becomes U-shaped starting with the third quarter of 2008, when we observe a marked downward trend across all maturities. From the mid-2010, real risk premia turn negative and remain such until the end of the sample. This pattern is consistent with

${ }^{4}$ Distinct from us, they construct realized Treasury volatility measures from high-frequency (intraday) data and use the MOVE Index implied volatility for the risk-neutral expectation. 
the negative nominal term premium reported by Durham (2013) and Adrian et al. (2013). ${ }^{5}$ The inclusion of the macro expectations is key to capture the marked decline in real risk premia in the last part of the sample, as this appears to be missed by models featuring only stochastic volatility, such as Haubrich et al. (2012). Notably, inflation and real risk premia are only weakly correlated, and load differently on standard predictors of bond risk premia.

We also find a significant link between inflation expectations (under the physical measure) and stochastic volatility. Thus, our paper contributes to the literature that studies the determinants of expected inflation, and its relation with risk premia (see e.g. Ang et al. (2008), Chernov and Mueller (2012), Ajello et al. (2014), Cieslak and Povala (2015), and Fleckenstein et al. (2017)).

In the final part of the paper, we present a series of model extensions in several directions. In particular, we squarely look at the effect of the financial crisis by re-estimating the model on the 2007-2010 period. During this period, the relation between risk premia and volatility turns negative at short horizons, as expected during flight-to-safety episodes that alter the risk-return tradeoff to stocks and bonds (see e.g. Campbell et al. (2009)). We further use inflation swaps data in place of TIPS as an alternative proxy for real rates in the post-2004 period. For inflation risk premia, the estimated term structure using either data is almost overlapping, whereas for real risk premia we find a similar shape of the term structure, but the level differs by some 20bps at the long-end. The estimated dynamics of the risk premia and the conclusions we draw regarding the role of the volatility and macroeconomic factors also remain valid.

\section{The Model}

In this section, we outline our term structure model. Section 1.1 describes the data-generatingprocess for the driving latent variables and risk premia. Next, Section 1.2 presents the implied no-arbitrage term structure for nominal and real rates, and risk premia.

\footnotetext{
${ }^{5}$ For the most recent period, updated (negative) premia are found at http://libertystreeteconomics.newyorkfed.org/2014/ 05/treasury-term-premia-1961-present.html. See also Kim and Wright (2005) and https://www.federalreserve.gov/pubs/ feds/2005/200533/200533abs.html.
} 


\subsection{State Variables and Macro Factors}

We assume that the economy is driven by the following four economic forces: the real interest rate, $r$; the expected inflation rate, $\pi$; the conditional mean of output growth, $\mu$, which reflects investors' expectations regarding the evolution of the real economy; and a variance factor, $v$, which drives the conditional volatility of all other variables. In addition to being jointly related in the diffusion component through $v$, the factors potentially affect each other in the conditional mean (drift). As argued above, various studies link either of these factors to the dynamics of real and nominal yields. We consider all of them simultaneously to explain the cross-section and time-series of bond prices (yields) and their volatilities.

Furthermore, we introduce a fifth state variable $\ell$ that accounts for specific features of the market for TIPSs, which we use later in our estimation strategy. As documented by D'Amico et al. (2010), during the first few years after its creation in 1997 the TIPS market suffered from a lack of liquidity with respect to the market of nominal Treasury bonds. A similar view is advanced by Campbell et al. (2009) and Christensen and Gillan (2011), who examine the abnormal behaviour of the TIPS market at the peak of the financial crisis. This evidence suggests that occasional disruptions and liquidity dry-ups may break the link between TIPS and real rates. Ignoring these effects in our modeling framework may mar our inference on the other factors when the model is asked to fit TIPS data. Therefore, we let $\ell$ enter the pricing of TIPS, but not that of nominal and real yields. In order to separately identify this component, we allow its conditional volatility and (potentially) mean to be related to the volatility factor only.

We collect the five latent factors in the vector $X=(v \mu \pi r \ell)^{\prime}$. In the notation of Dai and Singleton (2000), the dynamic of $X(t)$ under the physical probability measure evolves according to the following $A_{1}(5)$ specification:

$$
d X(t)=K(\Theta-X(t)) d t+\Xi \sqrt{S(t)} d W(t) .
$$

In the $(5 \times 5)$ matrix $K$ of mean-reversion coefficients, we impose that all off-diagonal elements involving the factor $\ell$ except $k_{5,1}$ are zero ${ }^{6}$ - that is, as mentioned above we allow only the volatility

$\overline{{ }^{6} \text { We thus impose that } k_{5, i}=0 \text { for } i=\{2,3,4\} \text { and } k_{j, 5}}=0$ for $j=\{1,2,3,4\}$. 
factor to affect the drift of $\ell$. The vector $\Theta$ of long-run means is $(5 \times 1)$; $\Xi$ is diagonal $(5 \times 5)$; and $S(t)$ is diagonal $(5 \times 5)$ with the element in position $(i, i)$ given by $[S(t)]_{i i}=\beta_{i}^{\prime} X(t)$, with $\beta_{i}$ denoting the $i$-th column of the $(5 \times 5)$ matrix $\beta$ which has ones in the first row and zeros elsewhere. The brownian shocks to the four economic factors are allowed to be correlated, but they are orthogonal to shocks to the liquidity factor. We denote $\Omega$ the resulting $(5 \times 5)$ covariance matrix of $d W(t)$. If we define $\Sigma=\operatorname{Chol}(\Xi \Omega \Xi)$, where Chol is the Cholesky decomposition, we can rewrite the model as:

$$
d X(t)=K(\Theta-X(t)) d t+\Sigma \sqrt{S(t)} d z(t)
$$

where now $d z(t)$ denotes a vector of independent brownian motions. Our specification thus implies that $v$ follows a non-negative square-root process which drives the conditional volatility of the other, conditionally gaussian state variables. Therefore, stochastic volatility enters the expectation of future interest rates either through the drift term or by introducing conditional heteroskedasticity. The possibility that stochastic volatility feeds back to the conditional mean of the macro series and yields is consistent with the model and the empirical evidence presented in Creal and Wu (2017).

We explicitly model the dynamics of the price level and output growth. In common with most term structure models including inflation (such as, for example, Pennacchi (1991) and Ang et al. (2008)), we assume that the exogenously given process for the price level is supported by the underlying equilibrium in the money market. For the real economy, we assume that there exists a single technology producing a single physical good and that production output follows a stochastic process with a time-varying conditional mean. The expected inflation rate $\pi$ and the conditional mean of output growth $\mu$ are then defined as the stochastic drift components of the price level and production output processes, which follow correlated Ito processes whose variance is affine in the variance factor $v$ :

$$
\begin{aligned}
& \frac{d p}{p}=\pi(t) d t+\sigma_{0, p} d z_{0, p}+\sigma_{1, p} \sqrt{v(t)} d z_{1, p} \\
& \frac{d q}{q}=\mu(t) d t+\xi\left(\sigma_{0, q} d z_{0, p}+\sigma_{1, q} \sqrt{v(t)} d z_{1, p}\right)+\sqrt{1-\xi^{2}}\left(\sigma_{0, q} d z_{0, q}+\sigma_{1, q} \sqrt{v} d z_{1, q}\right)
\end{aligned}
$$

with $z_{0, p}, z_{1, p}, z_{0, q}$ and $z_{1, q}$ as uncorrelated Brownian motions. This choice implies that the stochastic volatility factor also captures time-variation in macroeconomic risk. We collect the corresponding 
parameters in the vector $\Phi=\left(\sigma_{0, p}, \sigma_{1, p}, \sigma_{0, q}, \sigma_{1, q}, \xi\right)$.

To close the model, we need to specify the functional form of the instantaneous market price for risk. We adopt the general "essentially affine" specification of Duffee (2002) (see also Duarte (2004)):

$$
\Psi(t)=\sqrt{S^{-}(t)}\left(\Lambda_{0}+\Lambda_{1} X(t)\right)
$$

where $S^{-}(t)$ denotes the inverse of $S(t), \Lambda_{0}$ is a $(5 \times 1)$ vector of constant risk premia, and $\Lambda_{1}$ is $(5 \times 5)$ with the same off-diagonal zero constraints as in $K$. This formulation is particularly appealing as it allows risk premia to vary over time, and potentially to change sign. Extant studies find risk premia to nominal bond that exhibit significant time variation and may even turn negative (see e.g. Cochrane and Piazzesi (2005) and Ludvigson and Ng (2009)).

The affine specification in (2)-(5) leads to a stochastic process of $X(t)$ under the risk-adjusted probability measure $\mathbb{Q}$ whose drift and diffusion terms are also affine. In fact, Girsanov's theorem implies that the dynamics of $d X(t)$ under $\mathbb{Q}$ follows:

$$
d X(t)=(\widetilde{K} \widetilde{\Theta}-\widetilde{K} X(t)) d t+\Sigma \sqrt{S(t)} d \widetilde{z}(t)
$$

where $\widetilde{K}=K+\Sigma \Lambda_{1}, \widetilde{K} \widetilde{\Theta}=K \Theta-\Sigma \Lambda_{0}$, and $d \widetilde{z}(t)$ is the risk-neutral Brownian motion. ${ }^{7}$

\subsection{Term Structure and Risk Premia}

Following Benninga and Protopapadakis (1983), we obtain the model's implication for the pricing of nominal and real bonds by imposing that the instantaneous nominal interest rate $y$ equals the sum of the instantaneous expected inflation rate $\pi$, real interest rate $r$, and inflation risk premium irp. The last term is related to the correlation between output and price level and to the volatility of the price level. Combining (2) with (3)-(4) delivers an instantaneous inflation risk premium that

\footnotetext{
${ }^{7}$ Unlike recent literature that advocates the presence of hidden factors in the term structure (see e.g. Duffee (2011) and Joslin et al. (2014)), we do not explicitly impose the restriction that some state variables affect bond risk premia but do not enter the pricing of bonds.
} 
is linear in the variance factor $v$ :

$$
\begin{aligned}
i r p & =-\frac{1}{d t}\left(\operatorname{Cov}_{t}\left\{\frac{d p}{p}, \frac{d q}{q}\right\}+\operatorname{Var}_{t}\left\{\frac{d p}{p}\right\}\right) \\
& =-\sigma_{0, p}\left(\xi \sigma_{0, q}+\sigma_{0, p}\right)-\sigma_{1, p}\left(\xi \sigma_{1, q}+\sigma_{1, p}\right) v \equiv \varepsilon_{0}+\varepsilon v
\end{aligned}
$$

This result allows us to write the instantaneous nominal interest rate $y$ as an affine function of the state vector:

$$
y(t)=\delta_{0}+\delta^{\prime} X(t)
$$

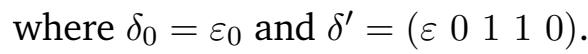

The affine risk-neutral dynamics in (6) together with (8) imply that the model falls in the class of affine term structure models (Piazzesi (2010)). The equilibrium arbitrage-free price of a nominal unit discount bond with time to maturity $\tau$ at time $t$ has an exponentially affine closedform solution:

$$
F(\tau ; t)=\exp \left[\bar{A}_{Y}(\tau)-\bar{B}_{Y}^{\prime}(\tau) X(t)\right]
$$

The coefficients $\bar{A}_{Y}(\tau)$ and $\bar{B}_{Y}(\tau)$ depend on the underlying model parameters and solve the following system of ordinary differential equations (ODEs):

$$
\begin{aligned}
\frac{d \bar{A}_{Y}(\tau)}{d \tau} & =-(\widetilde{K} \widetilde{\Theta})^{\prime} \bar{B}_{Y}(\tau)-\delta_{0} \\
\frac{d \bar{B}_{Y}(\tau)}{d \tau} & =-\widetilde{K}^{\prime} \bar{B}_{Y}(\tau)+\frac{1}{2} \sum_{i=1}^{5}\left[\Sigma^{\prime} \bar{B}_{Y}(\tau)\right]_{i}^{2} \beta_{i}+\delta
\end{aligned}
$$

The nominal term structure is therefore affine in the state vector:

$$
Y(\tau ; t)=A_{Y}(\tau)+B_{Y}^{\prime}(\tau) X(t)
$$

where $A_{Y}(\tau) \equiv-\bar{A}_{Y}(\tau) / \tau$ and $B_{Y}(\tau) \equiv \bar{B}_{Y}(\tau) / \tau$.

From expression (8), we obtain the equilibrium real rates $R(\tau ; t)$ by solving the system of ODEs (10) subject to the constraints $\delta_{0} \stackrel{R}{=} 0$ and $\delta^{\prime} \stackrel{R}{=}\left(\begin{array}{lllll}0 & 0 & 0 & 1 & 0\end{array}\right)$ :

$$
R(\tau ; t)=A_{R}(\tau)+B_{R}^{\prime}(\tau) X(t)
$$


The breakeven rate is defined as $H(\tau, t)=Y(\tau, t)-R(\tau ; t)$. Note that by the definition of $\delta^{\prime}$, the liquidity factor does not enter the pricing of either nominal, real, or breakeven rates. We create a wedge between TIPS and real rates by allowing the factor $\ell$ to affect the pricing of TIPS. That is, equilibrium TIPS rates $T(\tau ; t)$ obtain by solving the system of ODEs (10) subject to the constraints $\delta_{0} \stackrel{T}{=} 0$ and $\delta^{\prime} \stackrel{T}{=}\left(\begin{array}{lllll}0 & 0 & 0 & 1 & 1\end{array}\right)$ :

$$
T(\tau ; t)=A_{T}(\tau)+B_{T}^{\prime}(\tau) X(t)
$$

This expression clarifies that for a given $\tau$, higher values of $\ell$ are associated with periods when TIPS are more imperfect proxies for real rates.

Turning to second moments, the diffusion term in the risk-adjusted dynamics of $X(t)$ is affine in $v$, which implies that nominal yield volatilities are time-varying and are driven by a single factor. More formally, the term structure of the variance of nominal yield changes under the risk-adjusted measure is given by:

$$
\mathbb{V}(\tau ; t)=B_{Y}^{\prime}(\tau)\left(\Sigma S(t) \Sigma^{\prime}\right) B_{Y}(\tau)
$$

Equally, the model delivers a closed-form solution for the term structure of the volatility of real interest rates that is also affine in $v$.

From the closed form expressions above, we obtain the term structure of inflation and real risk premia. Similarly to Haubrich et al. (2012), we define the inflation risk premium $\operatorname{IRP}(\tau ; t)$ as the difference between the breakeven rate under the risk-adjusted and physical probability measure, or:

$$
\operatorname{IRP}(\tau ; t)=H(\tau ; t)-H^{\mathbb{P}}(\tau ; t)
$$

where $H^{\mathbb{P}}(\tau ; t)=-\frac{1}{\tau} \ln \left(\mathrm{E}^{\mathbb{P}}\left[e^{-\int_{t}^{t+\tau}\left(y_{s}-r_{s}\right) d s} \mid I_{t}\right]\right)$. This difference depends crucially on the covariance between inflation and output growth rates, which captures the bond's ability to act as a hedge against a decrease in consumption.

Similarly, let $R^{\mathbb{P}}(\tau ; t)$ be the implied yield of a real zero coupon bond when the expectation is taken under the physical measure, or $R^{\mathbb{P}}(\tau ; t)=-\frac{1}{\tau} \ln \left(\mathrm{E}^{\mathbb{P}}\left[e^{-\int_{t}^{t+\tau} r_{s} d s} \mid I_{t}\right]\right)$. We then define the real risk premium $\operatorname{RRP}(\tau ; t)$ for a given maturity $\tau$ as the difference between the real rate $R(\tau ; t)$ and $R^{\mathbb{P}}(\tau ; t)$, or

$$
\operatorname{RRP}(\tau ; t)=R(\tau ; t)-R^{\mathbb{P}}(\tau ; t)
$$


Since the process for the state vector is affine under both measures, risk premia are linear functions of $X_{t}$. Moreover, it is important to note that unlike the instantaneous inflation risk premia in (7), state variables other than $v$ can affect $\operatorname{IRP}(\tau ; t)$ through their ability to predict future realizations of $v$ under the $\mathbb{P}$ or $\mathbb{Q}$ measure (i.e. to the extent they enter $K, \widetilde{K}$, or both).

\section{Data and Preliminary Statistics}

Our empirical analysis combines data on yields, yield volatilities, and macroeconomic forecasts.

First, we obtain data on U.S. Treasury and TIPS from Gurkaynak et al. (2007 and 2008). We use end-of-month observations on annualized zero coupon yields with maturities ranging from two to ten years over the sample period from January, 1999 to December, 2016. For TIPS yields, the shortest observed maturity was five years before January 2004, and two years afterwards.

Figure 1 displays the time series of the 2-year, 5-year, and 10-year nominal Treasury yields (Panel A) and TIPS yields (Panel B). The term structure of the nominal yields is moderately upward sloping (sometimes downward sloping) over the 1999-2000 and 2005-2007 periods. However, it becomes very steep during the 2001-2004 and 2008-2014 periods, with the spread between the 10 -year and the 1-year rate rising above 250bps.

In general, a declining trend in long-term nominal rates can be observed, which seems to be mainly originating from the behaviour of real rates. In fact, apart from the months following Lehman's default in September 2008, when there is a sudden and temporary increase, long-term TIPS yields decline from about $4 \%$ in 1999 to a range between $-1 \%$ and $+1 \%$ in 2016 . As a consequence of the 2008 financial crisis and the subsequent expansionary monetary policy, shortterm nominal rates remain close to zero during the post-2009 sample period.

Second, we construct estimates of realized yield volatility. A distinct feature of the model is the assumption of a latent factor driving the term structure of nominal, real, and inflation volatilities. To identify the factor, we rely on a standard realized volatility estimator computed as the standard deviation of daily changes in nominal Treasury yields within a given month. Panel C of Figure 1 displays these realized volatilities for the 2-year, 5-year, and 10-year bonds. Yield volatilities vary in the 50-150bps range for most of the sample, but experience a peak at about 300bps during 2008. 
Also noteworthy is the fact that the term structure of volatilities is downward sloping until 2008, and steeply upward sloping in the post-crisis period.

We augment realized volatilities with end-of-month quotations of the implied volatility of the 10-year Treasury-Note future options. This series avails ourselves of risk-adjusted market expectations of future nominal yield volatility, and therefore considerably enhances our identification of both $v$ and the risk premium parameters. The series is displayed in Panel $\mathrm{D}$ of the figure.

Third and finally, we capture the dynamics of expected inflation and real growth through the Philadelphia Survey of Professional Forecasters (SPF henceforth) data. To be precise, we use the median 1-year-ahead forecasts of annual GDP deflator and annual real GDP growth rates. This data is available on a quarterly basis. Panels $\mathrm{E}$ and $\mathrm{F}$ of the figure display the corresponding time series. Expected inflation rates increase by almost $1 \%$ in the $1999-2000$ period. They then drop to $1.5 \%$ around the time of the 2001 recession, before starting to rise up to $2.5 \%$ in $2007-2008$. A sharp decline follows the Lehman default, with inflation expectations near 1\%, before returning to a value close to $2 \%$ in the final part of the sample. The behaviour of expected real growth is similar, but with a much more pronounced drop in 2001 (from 3\% in the early 2000 to about 1\%) and especially at the end of 2008 (from about 3.5\% in mid-2006 to a minimum of about -1\%).

In Panel A of Table 1 we collect summary statistics of the data. Notably, on average, the term structures of nominal and TIPS yields are upward sloping, whereas the term structure of the volatility of nominal yields flattens at the long end. However, as stated above, there is great variability in the level and slope of the curves across the sample period. Inflation and GDP growth expectations average out at $1.85 \%$ and $2.62 \%$, respectively, with GDP growth rates that are nearly three times more volatile.

A relevant feature of the model is the presence of strong common components that drive timeseries fluctuations in the level of nominal and real yields, their conditional volatility, and inflation and output growth expectations. To formally explore this assumption, in Panel B of the table we look at the correlation structure of the data. In particular, we report the percentage of the total variation in the correlation matrix explained by the first four principal components. We first look at the level of nominal and TIPS yields. For the full term structure of nominal yields, three factors explain about $99 \%$ of the total variation, with the first factor being responsible for more than 
97\%. The long end of the term structure of TIPS yields (maturities from 5-year onward) is almost entirely spanned by a single factor, whose role however decreases to $97 \%$ when including also the short end (maturities from 2-year onward since January, 2004). When combining nominal and TIPS yields, three factors (post January, 2004) capture nearly $100 \%$ of the total variation across the 18 series. There is also a strong factor structure in the term structure of realized volatilities of nominal yields, as more than $90 \%$ of their variation is explained by the first principal component. The second factor also accounts for a significant 10\%. Finally, the last row of the panel combines the nominal and TIPS (maturities from 5-year onward) yields, nominal yield volatilities, and the macroeconomic forecasts - a total of 26 series. The first two principal components account for nearly $90 \%$ of total variation, and the third factor explains an additional $4 \%$. This result suggests that a low-dimensional state vector is responsible for the large bulk of fluctuations across such a relatively large array of series.

\section{Empirical Results}

In this section, we present the main empirical results of the paper. We first discuss the econometric approach in Section 3.1. We present the resulting estimates of the model parameters and state variables in Section 3.2, followed by statistics on the goodness of fit in Section 3.3. In Sections 3.4 to 3.6 we set out the properties of the estimated term structure of inflation expectations and risk premia.

\subsection{Estimation Method}

The model is estimated via Quasi Maximum Likelihood using the Kalman filter. This methodology has become a standard approach for the estimation of term structure models that feature unobservable state variables (see Duffee and Stanton (2012) for a review). We briefly describe here the overall setup of the estimation and the data that enter the filter. A formal description of the set of state and observation equations together with details on the implementation of the filter are presented in the Appendix.

Our system of observation equations includes the following series: i) nominal yields; ii) TIPS 
yields; iii) the realized variance of nominal yield changes; iv) the implied (risk-neutral) variance of the 10-year Treasury-Note future option; and v) macro expectations, as captured by the SPF forecasts. ${ }^{8}$ In the end, the system consists of twenty-seven equations prior to January, 2004, and thirty equations afterwards as the 2-year, 3-year, and 4-year TIPS yields become available. The observation equations are obtained by adding to the variables' model-implied expression an observation error, which is assumed to be normally distributed and homoskedastic. Also, the filter accommodates the fact that the SPF forecasts are available only at the quarterly frequency.

The five state equations are composed of the discrete time (monthly) equivalent of the continuoustime model in (2). In the estimation, we impose the cross-equation restrictions that originate from the (affine) expression for the conditional covariance matrix of the shocks to the state vector (see equation (A.5) in the Appendix). This is a constraint that helps us to better identify the volatility coefficients of the model. The inclusion of the implied variance of nominal yields among the observable variables fitted by the model also improves the identification of the variance coefficients of the stochastic processes of the real interest rate and the expected inflation rate, as well as the unobservable variance factor. This is crucial for capturing the time-varying behavior of risk premia.

\subsection{Estimated Parameters and State Variables}

Panel A of Table 2 reports the estimated parameter values, with underneath bootstrapped $p$-values in parentheses. Similarly to Haubrich et al. (2012), we find that the expected inflation rate and the real interest rate exhibit significant mean reversion, although in our case the half-life for a shock in the variables to return to its steady state is well above one year. We also find a relevant mean reversion in the volatility factor, and in the conditional mean of the output growth. The TIPS liquidity factor is the least persistent among the variables. The variance factor negatively affects the drift of all the other state variables, while expected output growth has a positive effect on the conditional mean of $v$ and a negative one on that of $\pi$ and $r$. Finally, the expected inflation and real rates positively affect each other in the drift and exhibit a similar sensitivity of their volatilities to the variance factor. The correlation between their instantaneous shocks is instead negative around -0.5. The correlation between shocks to $v$ and shocks to all other factors is instead positive, albeit

${ }^{8}$ In the literature, studies that use professional forecasts as $\mathbb{P}$-measure expectations of macroeconomic variables include Chun (2010) and Bhandari et al. (2016). 
not largely so. The estimated $\Lambda_{1}$ are all significant and negative in the main diagonal, which implies that risk-adjustment decreases the speed of mean reversion. We return to a specification test for risk premia in the next section.

Turning our attention to the estimated latent state variables, Figure 2 plots their time series, while Panel B of Table 2 reports summary statistics. We note that the variance factor (top-left plot) tracks quite closely the dynamics of yield volatilities, with distinct spikes during the early 2000s and the $2008-2009$ crisis periods. The average monthly volatility is about $1.9 \%$, but varies significantly throughout the period with a standard deviation of $0.60 \%$ and a maximum of about $4.5 \%$. Expected output growth (top-right plot) and the expected inflation rate (mid-left plot) also follow patterns similar to their corresponding SPF forecasts, averaging about 3\% and $2 \%$ respectively. The series are positively correlated at 0.55 , although this number drops to 0.41 if we exclude the last quarter of 2008 and the first quarter of 2009 when both of them (and in particular, expected growth) turn negative. In contrast, the correlation between $v$ and $\mu$ is negative at -0.44 , which implies that volatility generally tends to increase during business cycle downturns.

The real interest rate (mid-right plot) averages at a meager $0.40 \%$ during the period. This number, however, is the combination of decreasing real rates in the 0 to $5 \%$ range until 2004 , when the Federal Reserve aggressive monetary policy brought nominal short-term interest rates down from $6 \%$ to $1 \%$, compressing real rates between $0 \%$ and $3 \%$ during the 2004-2008 period. The instantaneous real rate remains negative from 2009 onward in correspondence with the near zero-rate FED monetary policy. We also note a positive trend in the later part of the sample when the FED started to release its quantitative easing policies.

The TIPS instantaneous (il)liquidity factor $\ell$ is displayed in the bottom-left plot of Figure 2 . The variable averages about $1.5 \%$ in the early part of the sample, turns to zero starting in 2005 , spikes at 3\% around Lehman's default, and then finally reverts back towards a $0.60 \%$ average. This pattern is entirely consistent with the arguments in D'Amico et al. (2010), Campbell et al. (2009), and Christensen and Gillan (2011) about liquidity issues at market inception and surrounding Lehman's collapse. Such correspondence is noteworthy given that $\ell$ is treated as latent variable in the filter and is not explicitly linked to an empirical proxy.

In Appendix Table A.1, we collect the model-implied loadings on the state vector (i.e., the $B(\tau)$ 
coefficients in the affine functions) for yields and risk premia. To ease their economic interpretation, in Table 3 we report the fraction of the variance of fitted yields and risk premia (at the $\tau=2-, 5-$, and 10-year maturity) that is accounted for by each factor. ${ }^{9}$ In Panel A, we see that the real interest rate $(75 \%)$ and expected inflation (30\%) are mostly responsible for variations in the 2-year nominal yield. However, the role of stochastic volatility increases with maturity and, for $\tau$ equal to 10 years, it becomes comparable to that of the real rate at about $30 \%$, while most of the variability of longterm nominal yields is explained by inflation expectations. The importance of $v$ at long maturities is confirmed for real yields in Panel B, where it accounts for about one third of the overall variance and is the second driving factor beyond $r$. For TIPS (Panel C), we see that the liquidity factor $\ell$ explains about one third of their overall variance. The term structure of the $B(\tau)$ coefficients on $\ell$ is downward sloping, which implies that the liquidity component of TIPS yields is indeed only 12bps on average across maturities.

We also compute the correlation of monthly changes in the economic factors with the first three principal components obtained from monthly changes in nominal yields. We observe that the first principal component (the "level" factor) is mostly related to expected inflation and real rates, with correlations of 0.53 and 0.66 respectively. The correlation with the second principal component (the "slope" factor) is positive for the real rate and expected output growth, a result in line with the stream of the literature linking output expectations to the slope of the term structure (see, e.g., Harvey (1988)). Finally, the variance factor has a negative correlation at -0.14 with the third principal component (the "curvature" factor). Interestingly, $\mu$ is positively correlated (around 0.2) with the fifth principal component, a result that is consistent with Adrian et al. (2013) and Joslin et al. (2014).

\subsection{Specification Test and Goodness of Fit}

To assess the model performance, we first look at the standard deviation of pricing errors, which are defined as the difference between actual and model-implied series. The first column of Table 4 reports this statistic for several combinations of the data. Across all maturities, the average standard deviation is $20 \mathrm{bps}$ for nominal yields, $12 \mathrm{bps}$ for TIPS yields, and 13.5bps for the volatility (realized

\footnotetext{
${ }^{9}$ This is calculated as the component VaR that is commonly used in risk management.
} 
and implied) of nominal yields. ${ }^{10}$ The standard deviation of pricing errors is quite larger at 46bps for SPF inflation, while SPF real GDP growth is quite precisely estimated with a standard deviation of only 4bps. When combining all series together in the last row of the table, the overall standard deviation amounts to less than 16bps.

To provide a visual inspection of the fit, Appendix Figure A.1 plots the actual and model-implied series for the 5-year maturity nominal yield, TIPS yield and realized yield volatility, the 10-year implied yield variance, the 1-year SPF inflation and real GDP expectations. Absolute errors on the nominal and TIPS yields are generally below 20bps. The fit of SPF series is quite different. For inflation, the model-implied series matches the drop in the actual forecasts at the peak of the crisis, but misses part of the variability afterwards. The model-implied output growth tracks instead very closely the corresponding SPF series.

Since the model imposes several moment restrictions, we test its adequacy through a standard specification test (see, for example, Duffee (2002) and Ang et al. (2008)). In particular, we apply a GMM-type test to assess the closeness of the estimated unconditional moments to the sample moments. The test is based on the point statistic $M=(m-\bar{m})^{\prime} \Xi^{-1}(m-\bar{m})$, where $\bar{m}$ are the sample estimates of the unconditional moments, $m$ are the model-implied unconditional moments, and $\Xi$ is the covariance matrix of the sample estimates of the unconditional moments, which is estimated using GMM with the Newey and West (1987) correction for heteroskedasticity and autocorrelation. Under the null hypothesis, the statistic is distributed as $\chi^{2}(n)$, where $n$ is the number of overidentifying restrictions.

The last two columns in Table 4 report the $p$-value of the test for the first and second moment, respectively, for the same combinations of series. Overall, the performance of the model is remarkably good for both the level and the volatilities of yields. The model also captures quite well the sample moments of output growth, and the average SPF inflation. Only in the case of the second moment of SPF inflation is the model rejected. When considering all series together, the $p$-value is 0.99 for the first moment, and 0.04 for the second moment. ${ }^{11}$

\footnotetext{
${ }^{10}$ In comparison, Haubrich et al. (2012) report standard deviations around 34bps for nominal yields for their stochastic volatility model that features a larger state vector, but does not incorporate macro expectations.

${ }^{11}$ As a further check, we verify the model's ability to match the volatility of the realized inflation and GDP growth series, although these are not directly used in the estimation. We find that the model-implied standard deviation of inflation is 93bps in annualized terms, compared to 99bps for the realized series. For GDP growth, the corresponding numbers are also very close at $250 \mathrm{bp}$ and $261 \mathrm{bps}$. Even smaller differences are observed for the standard deviation of conditional volatilities (the "vol of vol").
} 
Since the key parameters for the estimation of inflation and real risk premia are the market price of risk parameters $\Lambda_{0}$ and $\Lambda_{1}$, following Adrian et al. (2013) we apply a Wald test for the null hypothesis that the different rows of the vector and the matrix are equal to zero. In particular, we alternatively test the null hypothesis that i) the $i$-th row of $\Lambda_{0}$ and the $i$-th row of $\Lambda_{1}$ are jointly equal to zero, which would imply that the corresponding factor risk is not priced in the model; and ii) the $i$-th row of $\Lambda_{1}$ is equal to zero, i.e. a test on the time variation of the market price of risk associated with the corresponding factor. We find that both null hypotheses are strongly rejected for all state variables, with $p$-values below $1 \%$.

As a further metric of interest, we look at the model-implied maximal Sharpe ratio, defined as the Sharpe ratio that can be attained by a portfolio of bonds that span the payoff of the stochastic discount factor. Duffee (2010) documents that flexible affine term structure models featuring four or five Gaussian factors generate implausibly high Sharpe ratios, in the order of $10^{30}$. In Figure 3, we plot the time series of the maximal Sharpe ratio of simple monthly bond returns corresponding to the estimates of Table 2 and the filtered state variables of Figure $2 .{ }^{12}$ We note that the series does not take on extreme values, with a maximum of 1.10 and a full-sample average of 0.37 . These numbers mimic quite closely those reported by Adrian et al. (2013) for their five-factor model.

We conclude that despite a low-dimensional state vector, the model is capable of generating reasonable pricing errors. It is able to match well sample moment of nominal yields, real yields, nominal volatilities, and macro forecasts, without generating implausible risk compensations. We return to a robustness test of the model performance in Section 4.3 below.

\subsection{Inflation Expectations}

The left plot of Panel A of Figure 4 displays the time series of the model-implied inflation expectations under the physical probability measure. The term structure of inflation expectations is generally downward sloping, with the average spread between the 10-year and the 1-year maturity expected inflation rate being around -12bps. Short-term expectations are relatively volatile, whereas long-term expectations are quite stable and fluctuate in a range between 115bps and 215bps. A sudden change occurs at the peak of the financial crisis, when the shape of the term

\footnotetext{
${ }^{12}$ The diagnostic is computed as $\sqrt{\exp \left\{\Psi(t)^{\prime} \Psi(t) \tau\right\}}-1$, with $\tau$ equal to one month, as in Duffee (2010).
} 
structure of inflation expectations experiences a tilt. Following Lehman's default, short-term inflation expectations collapse and get close to zero, reflecting the market's fear of the possibility of a prolonged recession. The average term structure assumes a steep shape, with the spread between the 10-year and the 1-year maturity expected inflation rate rising to $100 \mathrm{bps}$.

To gauge the economic significance of the latent factors, we look at the impulse-response function (IRF) calculated as the reaction of the 10-year series to a positive one-standard-deviation shock to the state vector. The right plot in the panel reports the IRF for the 10-year inflation expectation. As expected, we observe a significant positive response to shocks in the expected inflation rate and in the volatility factor, whereas shocks in the real interest rate and in the conditional mean of output growth have a much smaller impact.

Analogous conclusions emerge by looking at the variance decomposition for inflation expectations in Panel D of Table 3. The expected inflation rate is by far the predominant factor in explaining the variance of 2-year inflation expectations. However, at the 10-year maturity the variance factor accounts for an economically significant $12 \%$. The result that stochastic volatility has an important role in driving the long-end of the curve lends further support to our modeling framework.

Our estimates reveal a change in the relation between expected inflation and real rates following the financial crisis. Before the third quarter of 2008, the correlation between monthly changes in expected inflation rates and corresponding (implied) real rates is only 0.15 at short maturities. In the period starting from the second quarter of 2009, this correlation drops to -0.30 . A similar change is not observed for long-term maturities, whose correlation with real rates remains relatively stable throughout the sample at around 0.40. As noted also by Haubrich et al. (2012), these findings are consistent with the Federal Reserve attempting to control short-term nominal rates after the financial crisis, which implies that changes in inflation expectations are offset by opposite changes in real interest rates. The positive relation observed for long maturities implies that longterm nominal yields tend to move more than one-for-one with inflation expectations. ${ }^{13}$ This reflects the long-term anticipation of an aggressive anti-inflationary monetary policy by the Federal Reserve in response to an increase in the forecasted inflation (Goto and Torous (2003)).

\footnotetext{
${ }^{13}$ In fact, if we regress nominal yields against real rates and inflation expectations of the same maturity, we observe slope coefficients significantly higher than 1 for maturities above 3 years. A similar result can be obtained by regressing forward nominal yields against forward real rates and forward inflation expectations.
} 
The model endogenously provides an estimate for the term structure of expected GDP growth rates. The average slope of such term structure is negative, with values decreasing from $2.5 \%$ at the 1-year maturity to $1.5 \%$ at the 10 -year maturity. The estimated expected inflation rates are positively correlated with the expected output growth rates, with correlations around 0.60 across maturities.

\subsection{Inflation Risk Premia}

The left plot of Panel B of Figure 4 shows the time series of the estimated term structure of inflation risk premia, computed as in (14). The average term structure has a moderate positive slope, with values around $12 \mathrm{bps}$ at the short end increasing up to $44 \mathrm{bps}$ at the long end. As in the case of inflation expectations, inflation risk premia suddenly drop in the autumn of 2008 as an effect of "flight-to-quality". This implies that a low, or even negative, inflation risk premium on Treasuries is required by investors during crisis periods. We squarely look at the implications of this flight-tosafety phenomenon during the crisis period in Section 4.1 below.

Our time-series of the 10-year inflation risk premium lies in between that reported in Grishchenko and Huang (2013) and Haubrich et al. (2012). Unlike Haubrich et al. (2012), however, we find short- and medium-term inflation risk premia that get closer to zero but remain slightly positive during the crisis period, compared to their reported minimum of -80bps at the 2-year maturity. Notably, our series are more stable throughout the sample, with a standard deviation of only 4.6bps in level and 1.5bps in first difference across the maturity spectrum, compared to the volatile inflation risk premia documented by other studies (e.g. Hordahl and Tristani (2010) and Christensen et al. (2010)). This evidence is consistent with the argument in Almeida et al. (2011) that accounting for stochastic volatility improves the estimation of risk premia.

The impulse-response function for the 10-year inflation risk premium (right plot) reveals that in the short term the inflation risk premium increases in response to a positive shock to each variable. However, shocks in the volatility factor and in the expected inflation rate have very persistent effects, whereas the effect of a shock to the real interest rate decays more rapidly over time. In the very short-term, a one standard deviation shock to the conditional mean of output growth has about half the impact of a shock to the volatility factor and the expected inflation rate. Then, it 
declines and changes sign.

A striking result of our estimates is the fact that the conditional mean of output growth is a key variable influencing the inflation risk premium. This is further testified by the variance decomposition in Panel E of Table 3. There, we observe that the $\mu$ factor accounts for about $20 \%$ to $30 \%$ of the variability of inflation risk premia across maturities. Its effect is second only to that of the expected inflation rate $\pi$, which explains about two-thirds of the variability at the medium and long-end. The positive (from above) and economically significant impact of output growth expectations on inflation risk premia is consistent with the evidence proposed by Hordahl and Tristani (2010), and with the idea that uncertainty about future unpredicted movements in inflation increases as expected business cycle conditions improve. Finally, the importance of the variance factor is increasing with maturities, reaching a non-trivial $13 \%$ for the 10 -year series.

To dig further into the nature of our risk premia estimates, we relate them to standard predictors in the literature on bond predictability. Specifically, Table 5 reports the results of the time-series regression of the average inflation risk premium (in bps) on the Cochrane and Piazzesi (2005) yield-based factor, the five Ludvigson and $\mathrm{Ng}$ (2009) macro-based factors, and a constant term. The factors are standardized to mean zero and variance unity to ease comparisons.

As we can see, the six variables explain a sizeable $76 \%$ of the overall variability of inflation risk premia. The Cochrane and Piazzesi (2005) factor enters with a positive and significant loading, while the real factor $F_{1}$ is significantly negatively related with a coefficient of -2.16 . Since $F_{1}$ is positively correlated with industrial production growth, its loading reflects a countercyclical component in inflation risk premia. The negative and significant coefficient on the $F_{4}$ factor, which is inversely related with inflation and the level of yields, also lines up with the importance of $\pi$ for IRP.

\subsection{Real Risk Premia}

The left plot of Panel C of Figure 4 displays the time series of the 2-, 5-, and 10-year estimated real risk premia from expression (15). The average term structure has a positive slope in the pre-crisis period, and is U-shaped starting from the third quarter of 2008. In the first period, the 2-year real risk premium fluctuates between -37bps and 34bps with an average around zero, whereas the 
10 -year real risk premium is always positive averaging at $52 \mathrm{bps}$ with a maximum of $114 \mathrm{bps}$. At the peak of the crisis, real risk premia exhibit a 20bps increase across all maturities. Afterwards, the premia decrease substantially and become negative at all maturities starting in 2010. The 10-year real risk premium reaches a minimum at -30bps in March 2013 and then, possibly as an effect of the FOMC assessments indicating an improvement in the pace of economic recovery, gradually reverts towards zero in the final part of the sample.

Looking at the whole sample period, we notice a marked decline in the level of real risk premia. Such a trend can be explained by the relationship between the real risk premium and the real interest rate, which also has a clear, declining tendency in the period under consideration. In fact, the correlation between monthly changes in the 10-year estimated real risk premium and the 10-year real rate is very high (0.89). The decline in real risk premia since the inception of the crisis could be the combined effect of a flight-to-quality phenomenon, which induces many investors to rebalance their portfolios in favour of Treasury bonds, and the credibility of the Federal Reserve monetary policy pegging short-term nominal rates near zero. During the same period, the 10-year nominal yield falls from 500bps to $150 \mathrm{bps}$, with the variations in the nominal risk premium, calculated as the sum of the real and the inflation risk premium, accounting for a significant proportion of the variations in the yield. In fact, consistent with the evidence presented by Durham (2013) and Adrian et al. (2013), the implied average nominal term premium turns negative since mid-2011, also as an effect of the large-scale asset purchases (LSAPs) program implemented by the Federal Reserve starting on March, 2009. As the estimated inflation risk premium fluctuates in a relatively narrow band and only temporarily falls at the peak of the financial crisis, the decline in the nominal risk premium is mainly due to the reduced real risk premium. ${ }^{14}$

The impulse-response function of the 10-year real risk premium is displayed in right plot of the panel. In the short term, the premium appears to be mainly affected by shocks to the volatility factor and to the real rate. However, while the former has a persistent and slowly decaying impact, the effect of the real rate is essentially absorbed within 10 years. The expected inflation rate has also an important effect at short-medium maturities. In fact, the variance decomposition in Panel F of Table 3 shows that $\pi$ accounts for $30 \%$ of the variability in 2-year bonds, but this fraction is

\footnotetext{
${ }^{14}$ According to Campbell et al. (2009), such a decline in the real risk premium is consistent with a prolonged recession and low real interest rates, which makes investors more concerned about shocks to long-term consumption growth than temporary shocks.
} 
declining with maturity. The real rate plays, as expected, the dominant role in driving real risk premia. At long maturities, the variance factor also has a non-negligible positive role, which is comparable at $16 \%$ to that played for inflation risk premia at the same maturity.

It is also noteworthy that inflation and real risk premia are not strongly correlated. Indeed, the correlation is negative at -0.20 at short maturities, and is mildly positive at 0.40 at the long-end. This is further confirmed by the regression results in Table 5. Compared to inflation risk premia, real risk premia appear to load significantly on different factors and with the opposite sign. Also, their relation to real activity as captured by $F_{1}$ is not statistically significant. Finally, the regression R-squared is down to just 30\%. This evidence underscores the benefits of breaking down nominal risk premia into their real and inflation components for the purpose of understanding their drivers and the distinct impact of volatility and macro expectations.

\section{Extensions}

In this section, we present a series of model extensions. We begin by squarely looking at the flight-to-safety phenomenon during the financial crisis in Section 4.1. Section 4.2 discusses the model-implied variance risk premium. In Section 4.3, we analyze the model stability by applying the 1999-2016 estimates to the 1985-1998 period. Finally, in Section 4.4 we use inflation swap data instead of TIPS in the model estimation.

\subsection{Risk Premia During the Financial Crisis}

Our previous analysis shows that latent stochastic volatility is an important determinant of both the level and time-variation in bond risk premia. In particular, a positive shock to volatility is associated with higher inflation and real risk premia (with different intensities). A natural question is whether this positive association extends also to very turbulent periods, such as the recent financial crisis, which are usually characterized by flight-to-safety dynamics. To investigate this argument, we separately estimate the model on the January, 2007 to December, 2010 subsample, i.e. four years of observations centered on the crisis period.

The resulting estimates reveal a significant change in the relation between bond risk premia and 
stochastic volatility. In particular, Figure 5 displays the impulse-response function to the 10-year inflation (Panel A) and real (Panel B) risk premium. As we can see, unlike other periods, expected returns to bonds in either nominal or real terms are now inversely related to risk or uncertainty, with the consequences being more long-lasting for real risk premia.

This negative effect of volatility is consistent with the view that in periods of crisis or marketwide distress, Treasury bonds provide a safe haven for investors whose demand pushes prices up thereby decreasing bond risk premia. This finding also lines up well with recent studies documenting instability in the risk-return tradeoff for equity during flight-to-safety periods (see, e.g., Ghysels et al. (2014)). Our conclusions contrasts with those from Adrian and Wu (2009), where the term structure of interest rate volatility is also fitted along with nominal and real yields. ${ }^{15}$

\subsection{Variance Risk Premia}

The model also endogenously delivers estimates of the variance risk premium $\operatorname{VRP}(\tau ; t)$. This is computed as $\operatorname{VRP}(\tau ; t)=\mathbb{V}(\tau ; t)-\mathbb{V}^{\mathbb{P}}(\tau ; t)$, where $\mathbb{V}^{\mathbb{P}}(\tau ; t)$ denotes the variance of changes in the implied yield of a nominal zero coupon bond when the expectation is taken under the physical measure. ${ }^{16}$ The left plot of Figure 6 displays the time-series of $\operatorname{VRP}(\tau ; t)$ for $\tau=2,5$, and 10 years. The term structure is generally upward sloping, with the 10-year series averaging about $0.43 \mathrm{bps}$. The series peaks at about $2.5 \mathrm{bps}$ during the financial crisis, and reaches its minimum towards the end of the sample as yields get closer to the zero bound.

Extant studies also look at the variance risk premium in the equity and fixed-income market defined as the realized return to a variance swap contract (see e.g., Bollerslev et al. (2009) and Mele et al. (2015)). This is computed as the difference between the ex-ante expectation of the variance under the risk-adjusted measure and ex-post realized variance. The solid line in the right plot of Figure 6 reports our model-implied variance risk premium for nominal bonds computed in such way. The premium is positive on average at $0.32 \mathrm{bps}$, but turns negative in some parts of the sample and in particular during the crisis, as realized volatility turned out to be much higher than expected. This is consistent with other studies such as Mele et al. (2015). In fact, during 2003-2016

\footnotetext{
${ }^{15}$ In particular, they find that the 10-year inflation risk premium is positively related to the GARCH estimator of interest rate volatility, with the premium rising above 150bps in the autumn of 2008.

${ }^{16}$ Since the volatility structure is entirely determined by $v, \operatorname{VRP}(\tau ; t)$ is an affine function of $v$ only.
} 
the correlation between our estimates and theirs is highly positive at 0.66 . In addition, the model allows us to compute the analogous variance risk premium for real bonds (dotted line in the plot). We note that the variance risk premium for real and nominal bonds share quite similar dynamics, with a full-sample correlation of 0.60 which drops at 0.45 during the crisis period.

\subsection{Testing the model stability}

To evaluate the stability of the model, we treat the 1999-2016 period as a training sample and apply the corresponding parameter estimates to data over January, 1985 to December, 1998. This is a truly demanding stress test since the level of nominal rates and volatilities are much different compared to our baseline sample. Thus, one may expect the model to do poorly even if it was the true data generating process, but some of the parameters were subject to instability or breaks.

We implement the test as follows. Our input data only consists of nominal yields, their realized volatilities, and the two SPF series, as data on TIPS yields and on the implied volatility of the 10year option future is not available during this period. Through the Kalman filter, and using the estimates from Table 2 - i.e., without re-estimating the model on 1985-1998 - we generate the time series of the five state variables during this period. Using these series and the coefficients in Table A.1 we construct yields and risk premia.

We find that the model passes this robustness test. The average standard deviation of pricing errors is $19 \mathrm{bps}$ for nominal yields and $12 \mathrm{bps}$ for their volatilities, which are smaller than those reported in Table 4 in absolute terms and relative to the series' averages (at 710bps and 95bps, respectively). The model also delivers a good fit of SPF real GDP (3bps), and to a less extent SPF inflation (34bps). From the specification tests, the null hypotheses of no difference between actual and fitted first and second moment for all series together is not rejected, with $p$-values of 0.40 and 0.53 , respectively. We take this evidence as indicative that the model captures salient features of the data.

Panel A of Figure 7 displays the maximal Sharpe Ratio. As in the post-1998 sample, it does not take on extreme values with an average of 0.35 and a maximum of 1.57 (in July, 1998). In panels $\mathrm{B}$ to $\mathrm{D}$, we plot the estimated real yields, inflation risk premia, and real risk premia. We note that all three series hit their maximum at the beginning of the sample, and then exhibit a distinct 
downward trend at medium-long maturities with some differences. The 10-year real rates and real risk premia decrease until 1987, when they revert back to about $6 \%$ and $1.3 \%$, respectively. In the early 1990s, they show a marked decline to their sample minimum towards the end of 1993, and rebound afterwards as a consequence of the 1994 bond crisis. On the contrary, the 1998 crisis of Russian bonds is followed by a decrease in estimated risk premia, which might reflect a flight-toquality effect. In contrast, long-term inflation risk premia show a secular decline. This pattern is consistent with the evidence in Ajello et al. (2014), and with the Great Moderation in U.S. inflation which has determined a sharp decrease in inflation volatility since 1984 (see Stock and Watson (2007)).

\subsection{Inflation Swaps}

Some studies rely on measures of breakeven inflation derived from inflation swaps, as this market is considered to be less affected by liquidity issues. In order to investigate the robustness of our findings to the choice of input data, we re-estimate the model on inflation swap rates. In particular, we use end-of-month observations on zero rates that are calculated from fixed-for-variable rate U.S. dollar inflation swaps with maturities ranging from one to 10 years (source: Bloomberg). As a downside of using inflation swap data is that they start only in July, 2004. We follow Haubrich et al. (2012) and include in the input data for the period between January, 1999 and June, 2004 only nominal yields derived from Treasury yields, realized and implied yield volatilities, and SPF expectations of inflation and GDP growth. In the model, we consider the specification with the four economic factors but without the additional liquidity variable, and treat inflation swap rates as clean proxies for breakeven rates. ${ }^{17}$

Panel A of Figure 8 displays the average term structure of inflation risk premia estimated using either TIPS or inflation swaps. As we can see, the two series are very close to each other at short maturities, and differ by less than 2bps at the 10-year maturity. In general, the cross-sectional and time-series patterns of inflation risk premia (not showed) when using either data are found to be very similar. Panel B of the figure shows that the average term structure of real risk premia is consistently U-shaped, with the two curves starting approximately at the same level. However, the

\footnotetext{
${ }^{17}$ Indeed, unlike TIPS, we find that incorporating the liquidity factor together with inflation swaps worsens the overall goodness of fit. This evidence is consistent with the view that this market is less prone to liquidity concerns.
} 
curve estimated with inflation swaps is shifted down by about 30bps at the long end.

In Panel C and Panel D we plot respectively the impulse-response function for the 10-year inflation and real risk premium. We note that the figures mimic quite closely those derived from TIPS. Similar considerations emerge when looking at the variance decomposition of yields. As far as goodness of fit is concerned, the average standard deviation of pricing errors to nominal yields is about 25 basis points, and thus 5bps higher than that from TIPS. ${ }^{18}$ Hence, our model delivers a better fit of nominal yields when using TIPS data, and taking fluctuations in their liquidity into account. This analysis reveals that our findings regarding the key role of stochastic volatility and macro factors in determining risk premia are robust to the use of inflation swaps data in the estimation.

\section{Concluding Remarks}

We develop a term structure model where the equilibrium real and nominal yields are affine functions of a five-dimensional state vector which includes a latent stochastic volatility factor and expected output growth. The model implies several cross-equation restrictions on the level of yields, their volatility under the risk-adjusted and physical measure, and market expectations of inflation and output growth. We exploit these restrictions through a Kalman filter estimation procedure on U.S. data over 1999-2016.

We document inflation risk premia that are time-varying, albeit in a less pronounced way than what documented by earlier studies, and on average significantly positive at about 40bps at the long-end. In contrast, real risk premia display a marked decline since the onset of the financial crisis, and have remained negative since mid-2010. The model-implied inflation, real, and variance risk premia are strongly related to stochastic volatility and conditional output growth at different maturities, suggesting that time-variation in the level of uncertainty and business cycle conditions play a crucial role in explaining the dynamic of risk compensation in the market for nominal and real bonds.

We also find that the model delivers relatively low pricing errors when applied to the 1985-1998

\footnotetext{
${ }^{18}$ Note that the liquidity factor does not enter the pricing of nominal yields also when using TIPS data. Hence, both models feature four factors for the pricing of the nominal term structure.
} 
period, for which data on inflation-linked securities is not available. This evidence suggests that the model could be used to retrieve the term structure of risk premia in countries where the market for real bonds is relatively young. 


\section{Appendix}

This appendix describes in detail the state-space representation of the model, and how quarterly survey data are aligned in its implementation.

\section{State-space representation of the model}

Our system is comprised of thirty observation (twenty-seven before Jan, 2004) equations, and five state equations. The thirty observation equations are composed as follows. Using the results of Section 1.2 we obtain: 9 equations for nominal yields (see (10)); 9 equations for TIPS yields (see (12)), which drop to 6 before Jan, 2004; and 9 equations for the variance of nominal yield changes (which obtain from (13) when setting $\Lambda_{t}=0$ ). An additional equation comes from the implied (risk-neutral) variance of the 10-year Treasury-Note future options. This series equals the expected $\mathbb{Q}$-measure average of the $v$ factor over the 10-year period (see (13) for $\tau=10$ ). Finally, the last two equations come from the expectations of the macroeconomic variables under the physical measure, which are also affine in $X(t)$ :

$$
\begin{aligned}
& \mathrm{E}\left[\ln \frac{p(\tau)}{p(0)} \mid I_{t}\right]=A_{p}(\tau)+B_{p}(\tau) X(t) \\
& \mathrm{E}\left[\ln \frac{q(\tau)}{q(0)} \mid I_{t}\right]=A_{q}(\tau)+B_{q}(\tau) X(t)
\end{aligned}
$$

We treat the median SPF forecasts of annual GDP deflator and annual real GDP growth rate as observable proxies for (A.1) and (A.2), respectively, with $\tau$ equal to 1 (the forecast horizon).

Given that the expressions listed above are all affine in the latent factors $X(t)$, the set of observation equations is obtained by adding a vector of observation errors $e(t)$ and can be compactly written as:

$$
\text { Observation eq.: } \quad Z(t)=A(\Gamma)+B(\Gamma) X(t)+e(t)
$$

where $Z(t)$ collects the 30 observable series at time $t$, and $A(30 \times 1)$ and $B(30 \times 4)$ solve the equations above and depend on the full set of model parameters $\Gamma$. We assume $e(t)$ to be normally distributed and homoskedastic.

The five state equations are composed of the discrete time (monthly) equivalent of the continuous time model in (2). The transformation is obtained by exploiting the solution to the stochastic differential equations that describe the dynamics of the variables, as in Christoffersen et al. (2014). The conditionally affine nature of the process implies that $X(t)$ follows a Markov Vector Autoregressive process, or:

$$
\text { State eq.: } \quad X(t)=a(\Gamma)+b(\Gamma) X(t-1)+u(t)
$$

where $a(5 \times 1)$ and $b(5 \times 5)$ also depend on the full set of model parameters $\Gamma$. An important feature of the model is the presence of time-varying conditional volatility that is driven by the state variables. This implies that the shock $u(t)$ is hetereroskedastic, with a conditional variance that is affine in $X(t)$, or:

$$
\operatorname{Var}_{t}(u(t))=V_{0}(\Gamma)+V_{1}(\Gamma) X(t-1)
$$

The parameters of the state-space model are estimated by maximum likelihood, with an approximate Kalman 
filter algorithm being used to calculate the values of the unobserved state variables. An approximate linear filtering is needed as the state vector has affine dynamics but is not Gaussian. In this scenario, an approximate transition equation can be obtained by exploiting the existence of an analytical expression of the first two conditional moments of the state vector (see, for example, Christoffersen et al. (2014) and Duffee and Stanton (2012)). It has been demonstrated through Monte Carlo simulations (see Duan and Simonato (1999)) that, although the parameter estimates are inconsistent, the impact of the approximation is negligible.

In the estimation, the cross-equation restrictions imposed in the model link each factor to observed variables. This allows identifying them, and rules out the possibility that two distinct set of parameters can give rise to observationally equivalent models. The only "pure" latent factor is the liquidity factor $\ell$, for which the admissibility constraints of Dai and Singleton (2000) are imposed and no feedback is allowed on the volatility and the other "observable" factors.

\section{Timing of survey data}

In the implementation of the Kalman filter, the survey data on 1-year ahead inflation and GDP growth are aligned with the last end-of-month observation of bond yields available at the date of the response to the survey's questionnaire of the Philadelphia Fed. The deadline for responses to the questionnaire is usually set in the second week of the middle month of each quarter. Therefore, as we use end-of-month data for bond yields and both realized and implied yield volatilities, the survey released in the first quarter (i.e., mid February) is aligned with bond yield information available at the end of January, the survey released in the second quarter (i.e., mid May) with bond yield data at the end of April, and so on. Therefore, we make sure that the survey data capture the same information set that is contained in the pricing (and volatility) of nominal yields and TIPS, and not future information. In months where the surveys are observed, they are incorporated in the measurement equation and treated as noisy estimates of the underlying latent expected 1-year ahead inflation and GDP growth. 


\section{References}

Adrian, T., R. Crump, and E. Moench. 2013. Pricing the term structure with linear regressions. Journal of Financial Economics 110:110-138.

Adrian, T., and H. Wu. 2009. The Term Structure of Inflation Expectations. Federal Reserve Bank of New York Staff Reports, Number 362.

Ajello, A., L. Benzoni, and O. Chyruk. 2014. Core and 'Crust': Consumer Prices and the Term Structure of Interest Rates. Federal Reserve Bank of Chicago Working paper 2014/11.

Almeida, C., J. Graveline, and S. Joslin. 2011. Do options contain information about excess bond returns? Journal of Econometrics 164:35-44.

Andersen, A. 2011. Inflation risk premia in the term structure of interest rates: Evidence from Euro area inflation swaps. Working paper, Copenhagen Business School.

Ang, A., G. Bekaert, and M. Wei. 2008. The Term Structure of Real Rates and Expected Inflation. The Journal of Finance 63:797-849.

Ang, A., and M. Piazzesi. 2003. A no-arbitrage vector autoregression of term structure dynamics with macroeconomic and latent variables. Journal of Monetary Economics 50:745-787.

Bansal, R., and I. Shaliastovich. 2012. A Long-Run Risks Explanation of Predictability Puzzles in Bond and Currency Markets. Review of Financial Studies 26:1-33.

Benninga, S., and A. Protopapadakis. 1983. Real and Nominal Interest Rates under Uncertainty: The Fisher Theorem and the Term Structure. Journal of Political Economy 91:856-867.

Bhandari, A., J. Borovička, and P. Ho. 2016. Identifying Ambiguity Shocks in Business Cycle Models Using Survey Data. University of Minnesota, New York University and Princeton University.

Bikbov, R., and M. Chernov. 2010. No-arbitrage macroeconomic determinants of the yield curve. Journal of Econometrics 159:166-182.

Bollerslev, T., G. Tauchen, and H. Zhou. 2009. Expected Stock Returns and Variance Risk Premia. The Review of Financial Studies 22:4463.

Buraschi, A., and A. Jiltsov. 2005. Inflation risk premia and the expectations hypothesis. Journal of Financial Economics 75:429-490.

Campbell, J., R. Shiller, and L. Viceira. 2009. Understanding inflation-indexed bond markets. Brookings Papers on Economic Activity :79-120.

Chen, R.-R., B. Liu, and X. Cheng. 2010. Pricing the term structure of inflation risk premia: Theory and evidence from TIPS. Journal of Empirical Finance 17:702 - 721.

Chernov, M., and P. Mueller. 2012. The term structure of inflation expectations. Journal of Financial Economics 106:367 - 394.

Christensen, J. H. E., and J. Gillan. 2011. TIPS Liquidity, Breakeven Inflation, and Inflation Expectations. Federal Reserve Board of San Francisco, Number 19.

Christensen, J. H. E., J. A. Lopez, and G. D. Rudebusch. 2010. Inflation expectations and risk premiums in an arbitrage-free model of nominal and real bond yields. Journal of Money, Credit, and Banking 42:143-178.

Christoffersen, P., C. Dorion, K. Jacobs, and L. Karoui. 2014. Nonlinear Kalman Filtering in Affine Term Structure Models. Management Science 60:2248-2268.

Chun, A. L. 2010. Expectations, Bond Yields, and Monetary Policy. Review of Financial Studies $24: 208-247$. 
Cieslak, A., and P. Povala. 2015. Expected Returns in Treasury Bonds. Review of Financial Studies 28:2859-2901.

Cieslak, A., and P. Povala. 2016. Information in the Term Structure of Yield Curve Volatility. The Journal of Finance 71:1393-1436.

Cochrane, J. H., and M. Piazzesi. 2005. Bond Risk Premia. American Economic Review 95:138-160.

Collin-Dufresne, P., R. S. Goldstein, and C. S. J. CS. 2009. Can interest rate volatility be extracted from the cross section of bond yields? An investigation of unspanned stochastic volatility. Journal of Financial Economics 94:47-66.

Creal, D., and J. C. W. Wu. 2017. Monetary Policy Uncertainty and Economic Fluctuations. International Economic Review 58:1317-1354.

Dai, Q., and K. J. Singleton. 2000. Specification Analysis of Affine Term Structure Models. The Journal of Finance 55:1943-1978.

D'Amico, S., D. H. Kim, and M. Wei. 2010. Tips from TIPS: the informational content of Treasury Inflation-Protected Security prices. Federal Reserve Board, Finance and Economics Discussion Series 19.

Diebold, F. X., G. D. Rudebusch, and S. B. Aruoba. 2006. The macroeconomy and the yield curve: a dynamic latent factor approach. Journal of Econometrics 131:309 - 338.

Duan, J.-C., and J.-G. Simonato. 1999. Estimating and Testing Exponential-Affine Term Structure Models by Kalman Filter. Review of Quantitative Finance and Accounting 13:111-135.

Duarte, J. 2004. Evaluating an Alternative Risk Preference in Affine Term Structure Models. Review of Financial Studies 17:379-404.

Duffee, G. 2002. Term premia and interest rate forecasts in affine models. The Journal of Finance 57:405-443.

Duffee, G. 2010. Sharpe ratios in term structure models. Johns Hopkins University working paper.

Duffee, G. 2011. Information in (and not in) the term structure. Review of Financial Studies $24: 2895-2934$.

Duffee, G., and R. Stanton. 2012. Estimation of dynamic term structure models. Quarterly Journal of Finance 2:1-51.

Durham, J. B. 2006. An Estimate of the Inflation Risk Premium Using a Three-Factor Affine Term Structure Model. Federal Reserve Board, working paper 42.

Durham, J. B. 2013. More on U.S. Treasury Term Premiums: Spot and Expected Measures. Federal Reserve Bank of New York, working paper 658.

Evans, M. 2003. Real Risk, Inflation Risk, and the Term Structure. Economic Journal 113:345-389.

Feldhütter, P., C. Heyerdahl-Larsen, and P. Illeditsch. 2016. Risk Premia and Volatilities in a Nonlinear Term Structure Model. Review of Finance p. rfw052.

Fleckenstein, M., F. A. Longstaff, and H. Lustig. 2017. Deflation Risk. The Review of Financial Studies 30:2719-2760.

Garcia, J., and T. Werner. 2010. Inflation risks and inflation risk premia. European Central Bank, working paper 1162.

Ghysels, E., P. Guérin, and M. Marcellino. 2014. Regime Switches in the Risk-Return Trade-off. Journal of Empirical Finance 28:118-138. 
Goto, S., and W. N. Torous. 2003. Evolving Inflation Dynamics, Monetary Policy, and The Fisher Hypothesis. AFA 2004 Meetings.

Grishchenko, O. V., and J.-Z. Huang. 2013. Inflation Risk Premium: Evidence from the TIPS Market. Journal of Fixed Income 22:5-30.

Gurkaynak, R., B. Sack, and J. Wright. 2007. The U.S. Treasury yield curve: 1961 to the present. Journal of Monetary Economics 54:2291-2304.

Gurkaynak, R., B. Sack, and J. Wright. 2008. The TIPS yield curve and inflation compensation. American Economics Journal: Macroeconomics 93:10-24.

Harvey, C. R. 1988. The real term structure and consumption growth. Journal of Financial Economics 22:305-333.

Haubrich, J., G. Pennacchi, and P. Ritchken. 2012. Inflation expectations, real rates, and risk premia: evidence from inflation swaps. Review of Financial Studies 25:1588-1629.

Heston, S. L. 1993. A Closed-Form Solution for Options with Stochastic Volatility with Applications to Bond and Currency Options. The Review of Financial Studies 6:327-343.

Hordahl, P., and O. Tristani. 2010. Inflation risk premia in the U.S. and the Euro area. Bank for International Settlements, working paper.

Hordahl, P., and O. Tristani. 2012. Inflation risk premia in the term structure of interest rates. Journal of the European Economic Association 10:634-657. Bank for International Settlements, working paper.

Jacobs, K., and L. Karoui. 2009. Conditional volatility in affine term-structure models: Evidence from Treasury and swap markets. Journal of Financial Economics 91:288 - 318.

Joslin, S., M. Priebsch, and K. J. Singleton. 2014. Risk Premiums in Dynamic Term Structure Models with Unspanned Macro Risks. The Journal of Finance 69:1197-1233.

Joyce, M., P. Lildholdt, and S. Sorensen. 2010. Extracting inflation expectations and inflation risk premia from the term structure: A joint model of the UK nominal and real yield curves. Journal of Banking and Finance 34:281-294.

Kim, D., and J. Wright. 2005. An arbitrage-free three-factor term structure model and the recent behavior of long-term yields and distant-horizon forward rates. Federal Reserve Board working paper 2005-33.

Ludvigson, S. C., and S. Ng. 2009. Macro Factors in Bond Risk Premia. Review of Financial Studies 22:5027-5067.

Mele, A., Y. Obayashi, and C. Shalen). 2015. Rates Fears Gauges and the Dynamics of Fixed Income and Equity Volatilities. Journal of Banking and Finance 52:256-265.

Newey, W. K., and K. D. West. 1987. A Simple Positive Semi-Definite, Heteroskedasticity and Autocorrelation Consistent Covariance Matrix. Econometrica 55:703-708.

Pennacchi, G. G. 1991. Identifying the Dynamics of Real Interest Rates and Inflation: Evidence Using Survey Data. The Review of Financial Studies 4:53-86.

Piazzesi, M. 2010. Affine term structure models. In Y. Ait-Sahalia and L. Hansen (eds.), Handbook of Financial Econometrics, pp. 691-766. Amsterdam: Elsevier.

Stock, J. H., and M. Watson. 2007. Why Has U.S. Inflation Become Harder to Forecast? Journal of Money, Credit, and Banking 39:3-34. 


\section{Table 1}

\section{Summary statistics and factor analysis}

Panel A reports summary statistics (in basis points) for the time series of nominal yields, TIPS yields, realized volatility of nominal yield, and macroeconomic forecasts that are used in the empirical analysis. The sample period is January, 1999 to December, 2016 for all series but TIPS, whose maturities shorter than 5-year start in January, 2004. Panel B reports the percentage of the total variation in the correlation matrix of the set of variables described in the first column which is explained by the first four principal components (PC1 to PC4). For TIPS we include only maturities from the 5-year onward in the 2nd and 4th row, and all maturities starting January, 2004 in the 3rd and 5th row. In parentheses, we report the total number of series.

\begin{tabular}{lrrrr}
\hline \multicolumn{2}{c}{ Panel A: Summary statistics } & & & \\
Series & Avg & Std. Dev. & Min & Max \\
\hline Nominal Yields & & & & \\
2-year & 230 & 194 & 19 & 665 \\
5-year & 303 & 161 & 63 & 663 \\
10-year & 390 & 136 & 150 & 670 \\
& & & & \\
TIPS Yields & 7 & 144 & -212 & 502 \\
2-year (from Jan, 2004) & 720 & 158 & -169 & 428 \\
5-year & 172 & 132 & -79 & 429 \\
10-year & & & & \\
Realized Volatility Nominal Yields & 75 & 43 & 10 & 311 \\
2-year & 92 & 36 & 32 & 259 \\
5-year & 93 & 32 & 36 & 215 \\
10-year & & & & \\
Macro Forecasts & 185 & 31 & 101 & 249 \\
SPF Inflation & 262 & 85 & -109 & 410
\end{tabular}

Panel B: Principal Component Analysis

\begin{tabular}{lcccc} 
Series & PC1 & PC2 & PC3 & PC4 \\
\hline Nominal Yields (9) & 97.19 & 2.72 & 0.08 & 0.00 \\
TIPS Yields (6) & 99.65 & 0.34 & 0.01 & 0.00 \\
TIPS Yields (9) since Jan, 2004 & 97.06 & 2.81 & 0.13 & 0.01 \\
Nominal\&TIPS (15) & 95.22 & 3.45 & 1.26 & 0.05 \\
Nominal\&TIPS (18) since Jan, 2004 & 90.19 & 6.50 & 2.97 & 0.28 \\
Realized Volatility Nominal Yields (9) & 90.23 & 9.24 & 0.49 & 0.04 \\
& & & & \\
Nominal\&TIPS\&Realized Volatility\&Macro Forecasts (26) & 56.86 & 33.18 & 4.37 & 2.91 \\
\hline
\end{tabular}


Table 2

Maximum likelihood estimates

Panel A reports the maximum likelihood estimates of the term structure model outlined in Section 1 . The coefficients are ordered as $[v ; \mu ; \pi ; r ; \ell]$. Underneath the estimates, bootstrapped $p$-values are reported in parentheses. Panel B reports summary statistics for the filtered state variables.

Panel A: Maximum likelihood estimates

Mean reversion

\begin{tabular}{cccccc}
\multicolumn{5}{c}{$K$} & $\Theta$ \\
\cline { 3 - 5 } 0.3422 & 0.0097 & -0.0410 & -0.0075 & - & 0.0042 \\
$(0.0030)$ & $(0.2994)$ & $(0.1042)$ & $(0.7105)$ & & $(0.0332)$ \\
-0.0610 & 0.3861 & -0.0471 & -0.2418 & - & 0.0496 \\
$(0.0057)$ & $(0.0064)$ & $(0.0140)$ & $(0.0026)$ & & $0.0018)$ \\
-3.2412 & -0.0149 & 0.4507 & 0.0367 & - & 0.0362 \\
$(0.0080)$ & $(0.2430)$ & $(0.0056)$ & $(0.0146)$ & & $(0.0036)$ \\
-5.3006 & -0.0305 & 0.0623 & 0.3507 & - & 0.0726 \\
$(0.0036)$ & $(0.0511)$ & $(0.0093)$ & $(0.0137)$ & & $0.0002)$ \\
-0.5014 & - & - & - & 0.1277 & 0.0014 \\
$(0.0111)$ & & & & $(0.0021)$ & $(0.7937)$
\end{tabular}

Volatilities and correlations

\begin{tabular}{c}
$\operatorname{diag}(\Xi)$ \\
\hline 0.0543 \\
$(0.1559)$ \\
0.3652 \\
$(0.0082)$ \\
0.5257 \\
$(0.0038)$ \\
0.5182 \\
$(0.0061)$ \\
0.1512 \\
$(0.0012)$
\end{tabular}

\begin{tabular}{ccccc}
\multicolumn{5}{c}{$\Omega$} \\
\hline 1 & 0.0037 & 0.0968 & 0.0033 & - \\
& $(0.0485)$ & $(0.0022)$ & $(0.2932)$ & \\
0.0037 & 1 & -0.0334 & -0.1105 & - \\
$(0.0485)$ & & $(0.0085)$ & $(0.0013)$ & \\
0.0968 & -0.0334 & 1 & -0.5119 & - \\
$(0.0022)$ & $(0.0085)$ & & $(0.0019)$ & \\
0.0033 & -0.1105 & -0.5119 & 1 & - \\
$(0.2932)$ & $(0.0013)$ & $(0.0019)$ & & \\
- & - & - & - & 1
\end{tabular}

\begin{tabular}{cc} 
& $\Phi$ \\
\hline$\sigma_{0, p}$ & 0.0060 \\
& $(0.0189)$ \\
$\sigma_{1, p}$ & 0.4181 \\
& $(0.0087)$ \\
$\sigma_{0, q}$ & 0.0005 \\
& $(0.1109)$ \\
$\sigma_{1, q}$ & 1.3991 \\
& $(0.0013)$ \\
$\xi$ & 0.6170 \\
& $(0.0151)$
\end{tabular}

Risk premia

\begin{tabular}{c}
$\Lambda_{0}$ \\
\hline 0.0002 \\
$(0.7978)$ \\
-0.0008 \\
$(0.7881)$ \\
-0.0005 \\
$(0.7948)$ \\
-0.0003 \\
$(0.7975)$ \\
0.0055 \\
$(0.6027)$
\end{tabular}

\begin{tabular}{ccccc}
\multicolumn{5}{c}{$\Lambda_{1}$} \\
\hline-0.5132 & -0.1079 & -0.0246 & 0.0370 & - \\
$(0.5770)$ & $(0.0084)$ & $(0.0136)$ & $(0.0097)$ & \\
0.3535 & -0.7939 & 0.7111 & -0.6731 & - \\
$(0.0116)$ & $(0.0067)$ & $(0.0051)$ & $(0.0187)$ & \\
-0.1184 & -0.0294 & -0.0529 & -0.0214 & - \\
$(0.0089)$ & $(0.0240)$ & $(0.0087)$ & $(0.0828)$ & \\
-0.2112 & -0.0972 & 0.4084 & -0.4682 & - \\
$(0.0043)$ & $(0.0061)$ & $(0.0138)$ & $(0.0054)$ & \\
-0.0755 & - & - & - & -0.7129 \\
$(0.0106)$ & & & & $(0.0092)$
\end{tabular}

Panel B: Summary statistics of state variables

\begin{tabular}{ccccc} 
& Avg & Std. Dev. & Min & Max \\
\hline$v$ & 0.0004 & 0.0003 & 0.0000 & 0.0020 \\
$\mu$ & 0.0303 & 0.0095 & -0.0133 & 0.0486 \\
$\pi$ & 0.0182 & 0.0057 & -0.0015 & 0.0296 \\
$r$ & 0.0040 & 0.0201 & -0.0217 & 0.0498 \\
$\ell$ & 0.0030 & 0.0059 & -0.0074 & 0.0302
\end{tabular}


Table 3

\section{Model-implied variance decomposition}

This table reports the model-implied contribution (in percentage) of each state variable to the overall variance of nominal yields, real yields, inflation expectations, inflation risk premia, and real risk premia at the 2-year, 5-year, and 10-year maturity. For all series but TIPS, the contribution of the liquidity factor $\ell$ is zero.

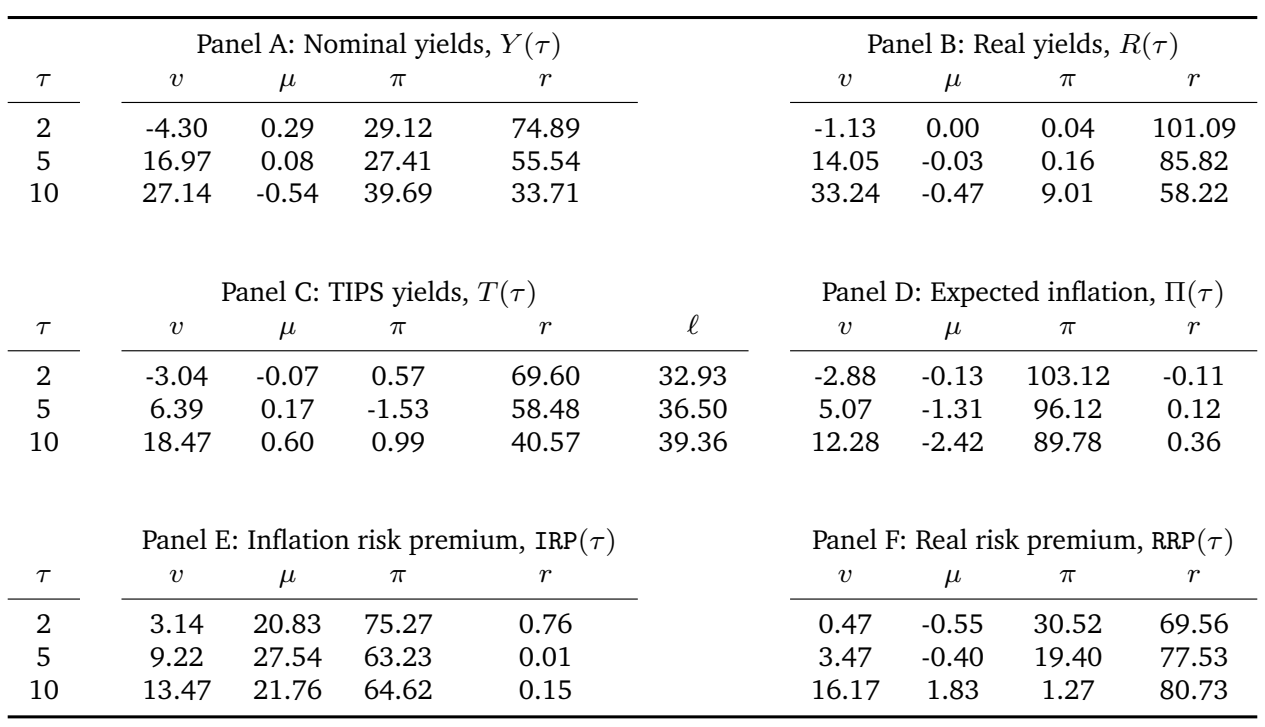


Table 4

\section{Goodness of fit and specification tests}

This table reports the average standard deviation of pricing errors (the differences between actual and model-implied series, $\widehat{\varepsilon}$ ) and the $p$-values of specification tests based on the model estimates for different series. The $p$-values are from the point statistic $M=(m-\bar{m})^{\prime} Q(m-\bar{m}) \sim \chi^{2}(n)$, where: $m$ and $\bar{m}$ indicate respectively the sample and model-implied unconditional moments; $Q$ is the covariance matrix of the sample estimates of the unconditional moments, estimated through GMM with the Newey and West (1987) correction; and $n$ is the number of over-identifying restrictions. The test is on the first and second moment.

\begin{tabular}{lccc}
\hline \multirow{2}{*}{ Series } & & \multicolumn{2}{c}{ Spec. test, $p$-value } \\
& Avg. Std $(\widehat{\epsilon})$ & First Moment & Second Moment \\
\hline Nominal Yields & 20.14 & 0.99 & 0.99 \\
TIPS Yields & 11.94 & 0.99 & 0.78 \\
Nominal \& TIPS & 16.04 & 0.99 & 0.99 \\
Volatility Nominal Yields & 13.54 & 0.65 & 0.13 \\
Nominal \& TIPS \& Volatility & 15.15 & 0.99 & 0.76 \\
SPF Inflation & 46.20 & 0.57 & 0.00 \\
SPF Real GDP Growth & 4.00 & 0.67 & 0.93 \\
Nominal \& TIPS \& Volatility \& SPF & 15.81 & 0.99 & 0.04 \\
\hline
\end{tabular}


Table 5

\section{Risk premia regressions}

This table reports the results of the time-series regression of the average inflation risk premium and real risk premium (in bps) on the Cochrane and Piazzesi (2005) yield-based factor and Ludvigson and $\mathrm{Ng}$ (2009) macro-based factors. The factors are standardized to mean zero and variance unity. Underneath the estimates, $p$-values based on Newey and West (1987) standard errors with 12 lags are reported in parentheses.

\begin{tabular}{cccccccc}
\hline & $\mathrm{CP}$ & $F_{1}$ & $F_{1}^{3}$ & $F_{3}$ & $F_{4}$ & $F_{8}$ & $R^{2}$ \\
\hline IRP & 2.5134 & -2.1563 & -0.9007 & -0.0662 & -0.7475 & 0.7957 & 0.76 \\
& $(0.0000)$ & $(0.0000)$ & $(0.0127)$ & $(0.7965)$ & $(0.0012)$ & $(0.0002)$ & \\
\multirow{2}{*}{$\operatorname{RRP}$} & 5.8507 & -6.1960 & 6.0106 & 5.6503 & -17.0046 & -5.2696 & 0.31 \\
& $(0.2307)$ & $(0.3511)$ & $(0.1563)$ & $(0.0000)$ & $(0.0000)$ & $(0.1407)$ & \\
\hline
\end{tabular}




\section{Figure 1. Time series of input data}

This figure displays the time series of nominal yields (Panel A), TIPS yields (Panel B), and realized volatility of nominal yield (Panel C) for the 2-year (dotted line), 5-year (dashed line), and 10-year (solid line) maturity. Panel D displays the implied volatility of the option on the 10-year T-note future. Panel E and F display, respectively, the median professional forecasts for 1-year ahead inflation (GDP deflator) and real GDP growth.
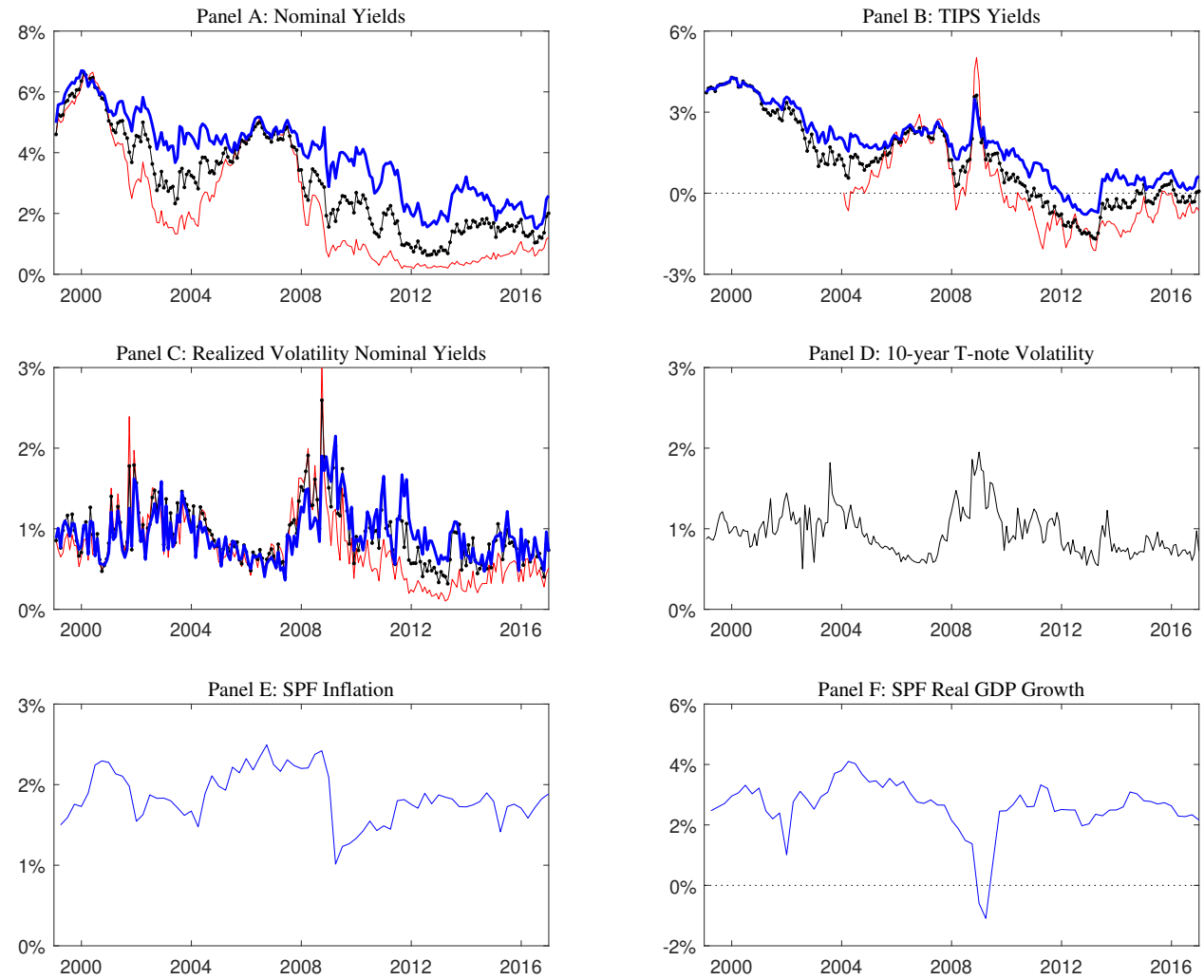
Figure 2. Estimates of latent state variables

This figure plots the Kalman Filter time-series estimates of the five latent state variables in the model: the variance factor $(v)$; expected output growth $(\mu)$; expected inflation rate $(\pi)$; the real rate $(r)$; and the (il)liquidity factor of TIPS $(\ell)$.
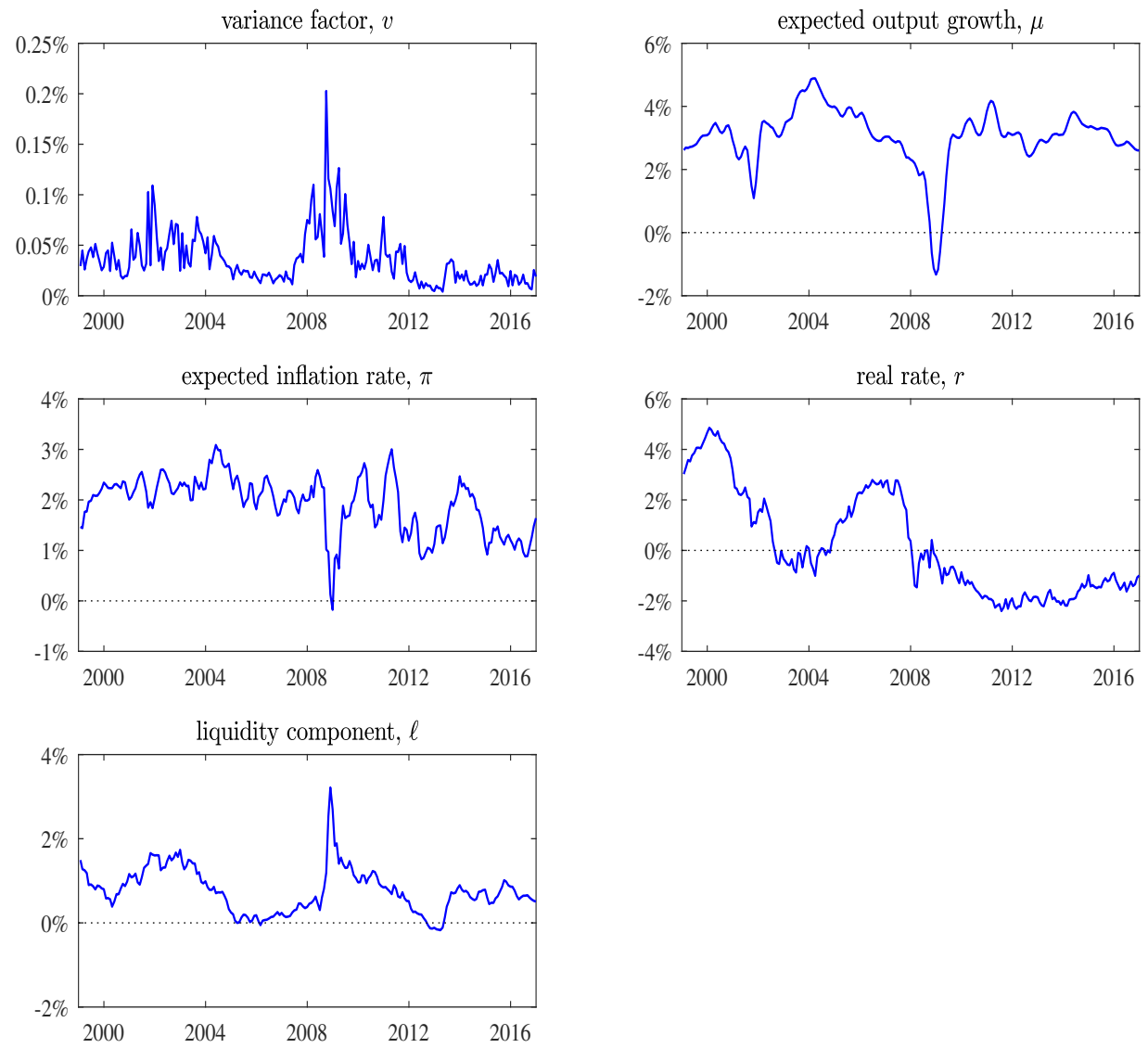


\section{Figure 3. Maximal Sharpe Ratio}

This figure displays the time series of the estimated maximal conditional model-implied Sharpe ratio for monthly simple bond returns, defined as in Section 3.3.

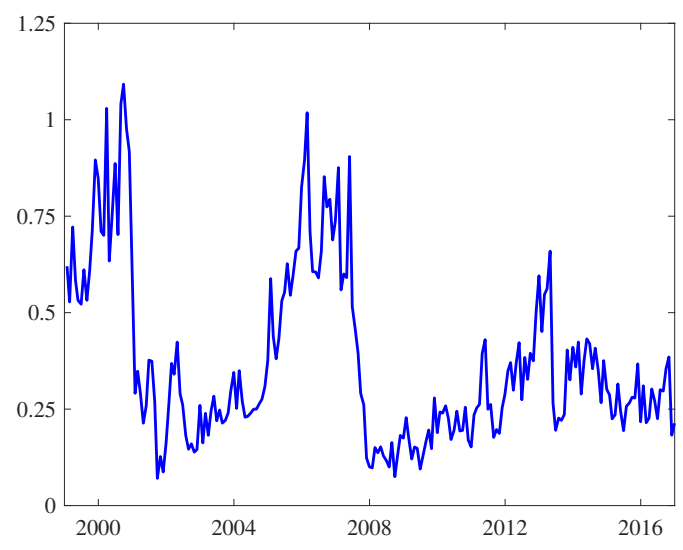




\section{Figure 4. Inflation expectations, inflation risk premium, and real risk premium}

This figure plots the model-implied $\mathbb{P}$-measure expected inflation (Panel A), inflation risk premium (Panel B), and real risk premium (Panel C). Within each panel, the left plot displays the estimated 2-, 5-, and 10-year series, whereas the right plot displays the impulseresponse function at the 10-year maturity following a one-standard deviation positive monthly shock to each state variable.

Panel A: Inflation Expectations
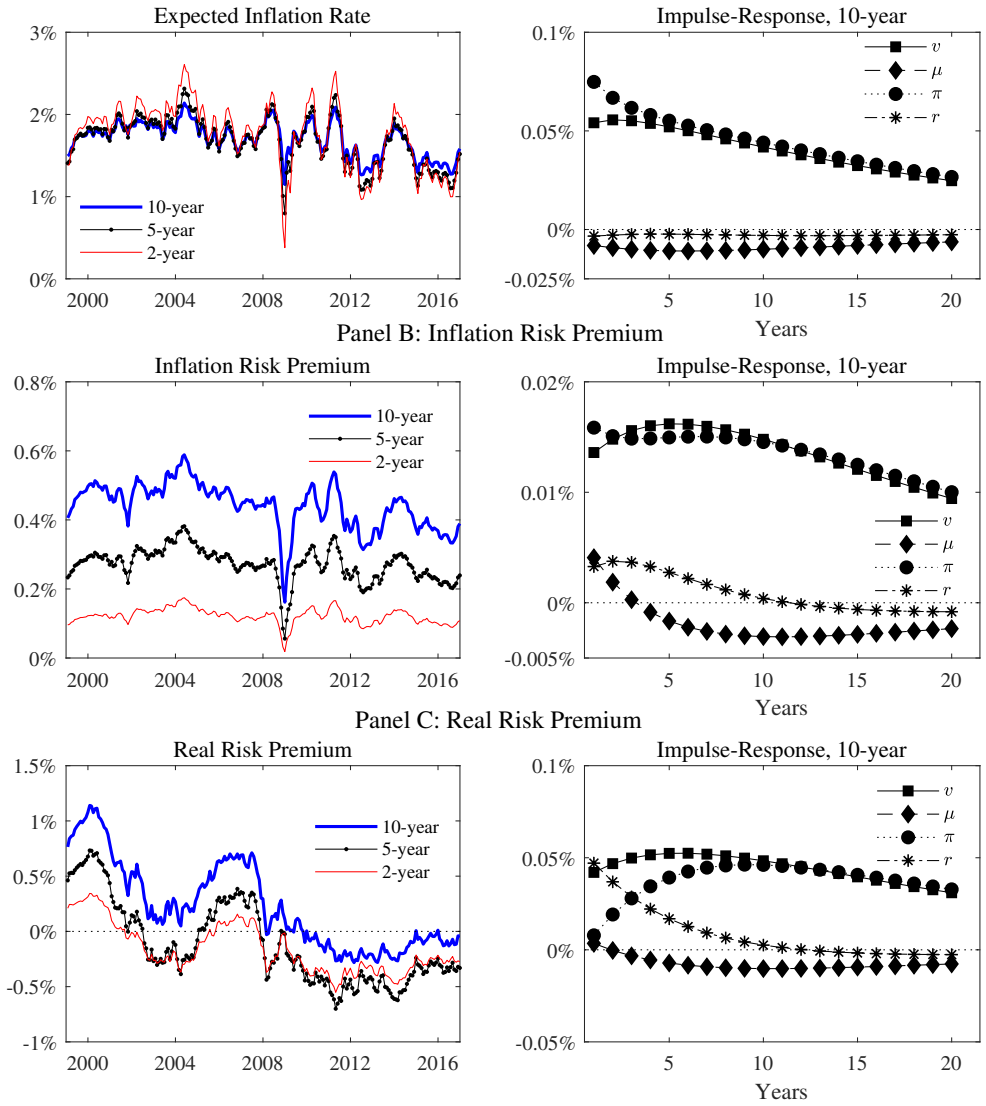
Figure 5. Risk premia during the crisis period

This figure plots the impulse-response function of the 10-year inflation risk premium (Panel A) and real risk premium (Panel B) following a one-standard deviation positive monthly shock to each state variable, when estimating the model over the January, 2007 to December, 2010 period.
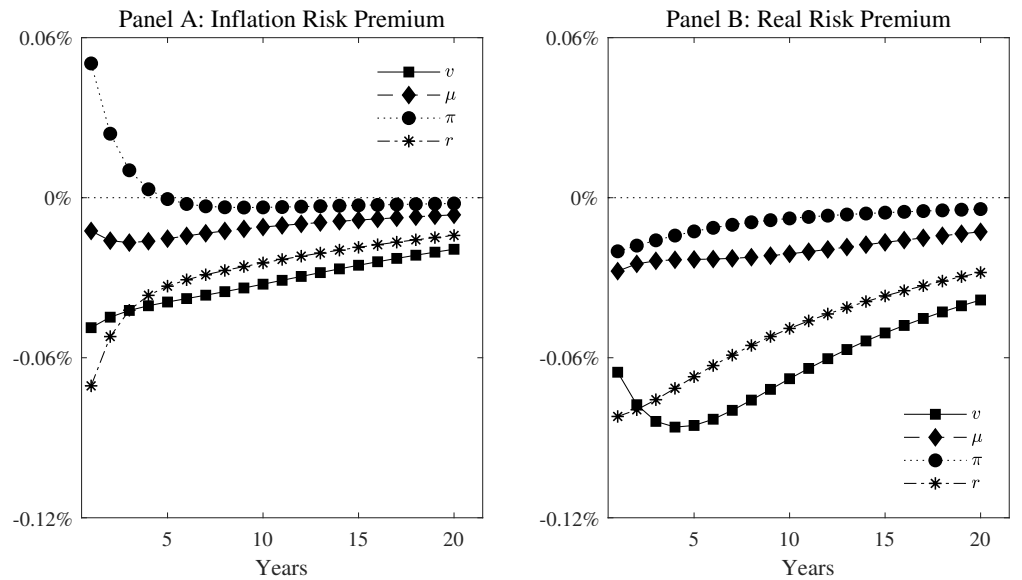


\section{Figure 6. Variance risk premium}

Panel A of this figure plots the model-implied variance risk premium at the 2-, 5-, and 10-year maturity, computed as the difference between the ex-ante expected variance of nominal yields under the risk-adjusted and physical measure. Panel B plots the model-implied realized variance risk premium at the 10-year maturity for nominal yields (solid line) and real yields (dotted line), computed as the difference between the ex-ante expected variance under the risk-adjusted measure and the ex-post realized variance.
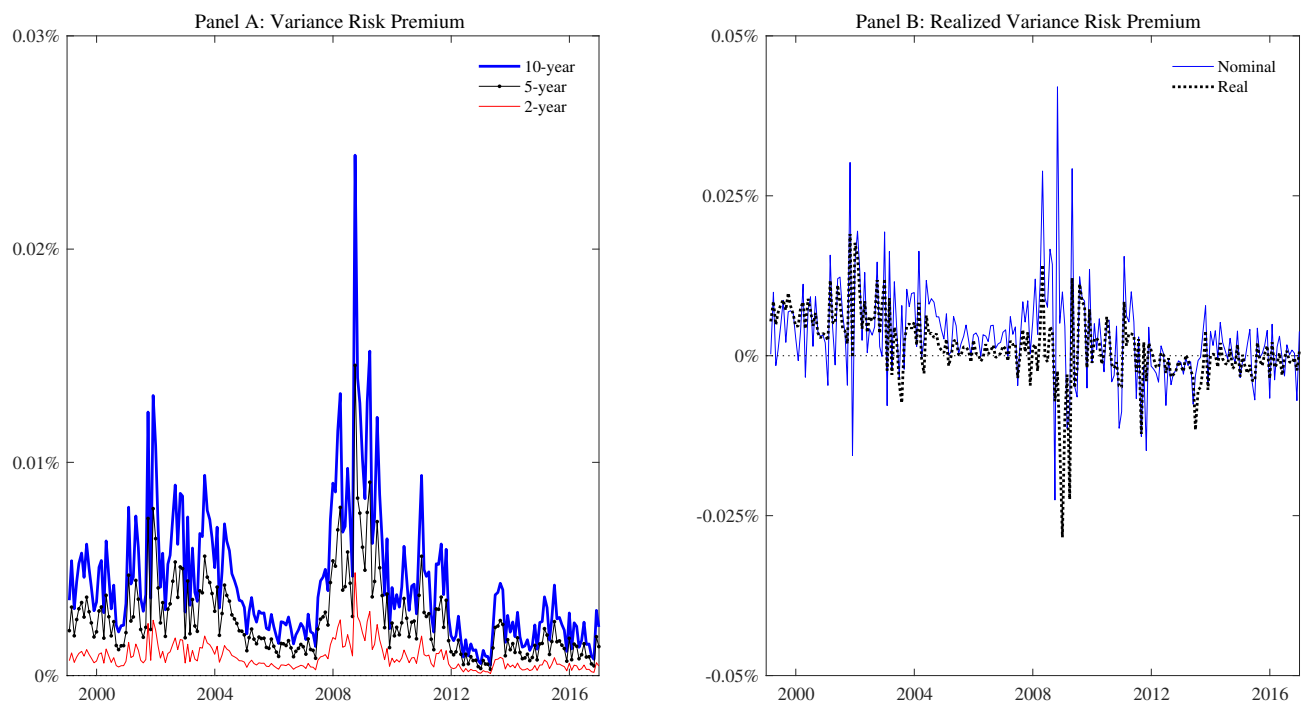


\section{Figure 7. Model-implied estimates, 1985-1998 period}

This figure displays the model-implied time series of maximal Sharpe Ratio (Panel A), real yields (Panel B), inflation risk premium (Panel C), and real risk premium (Panel D) when applying the estimates from Table 2 to the January, 1985 to December, 1998 period.
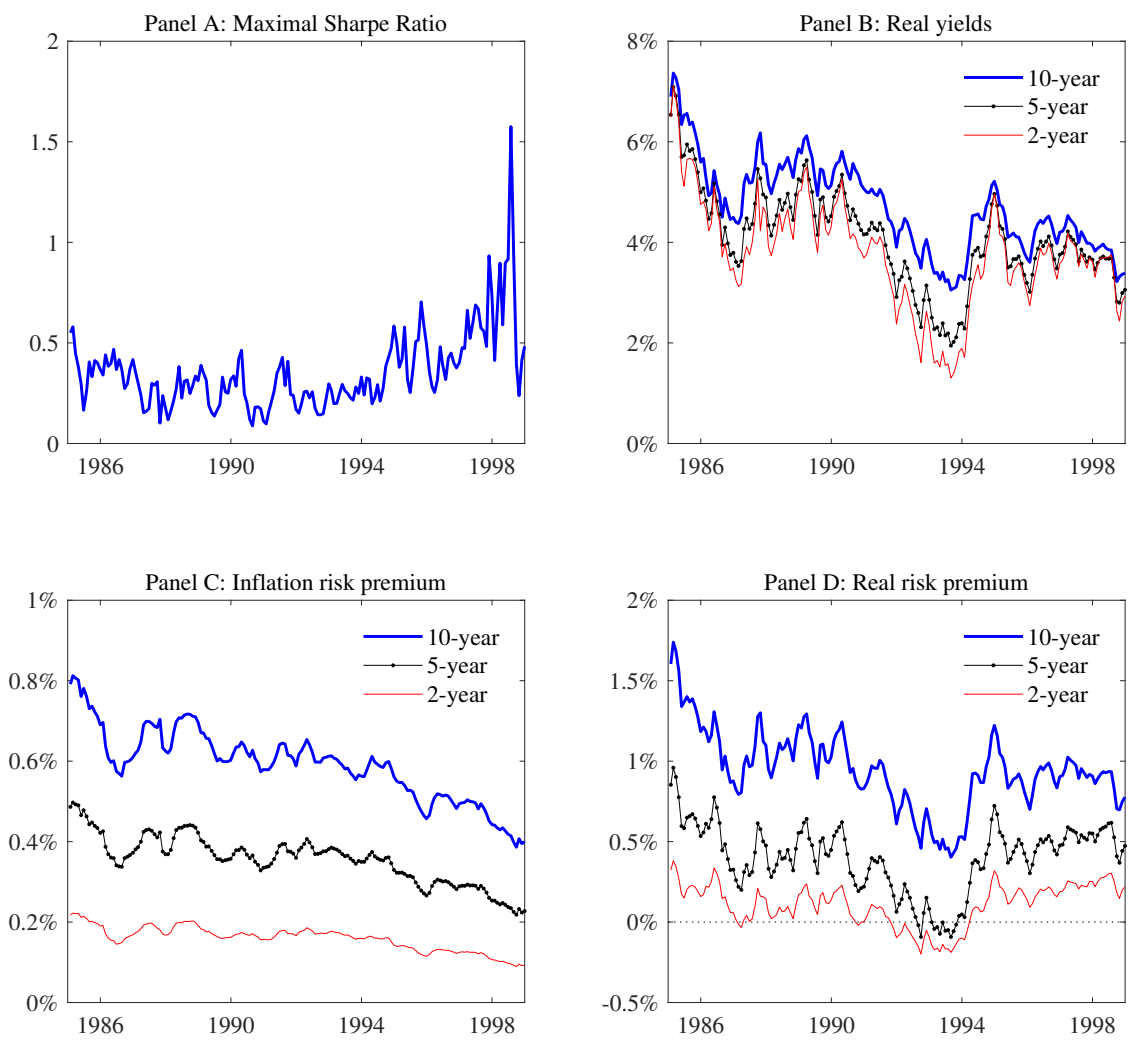


\section{Figure 8. TIPS versus inflation swaps}

Panels A and B of this figure display respectively the unconditional term structure of inflation risk premia and real risk premia when estimating the model on either TIPS or inflation swap data. Panels C and D display the impulse-response function following a onestandard deviation positive monthly shock to each state variable, respectively, for the 10-year inflation risk premium and 10-year real risk premium, when estimating the model on inflation swap data.
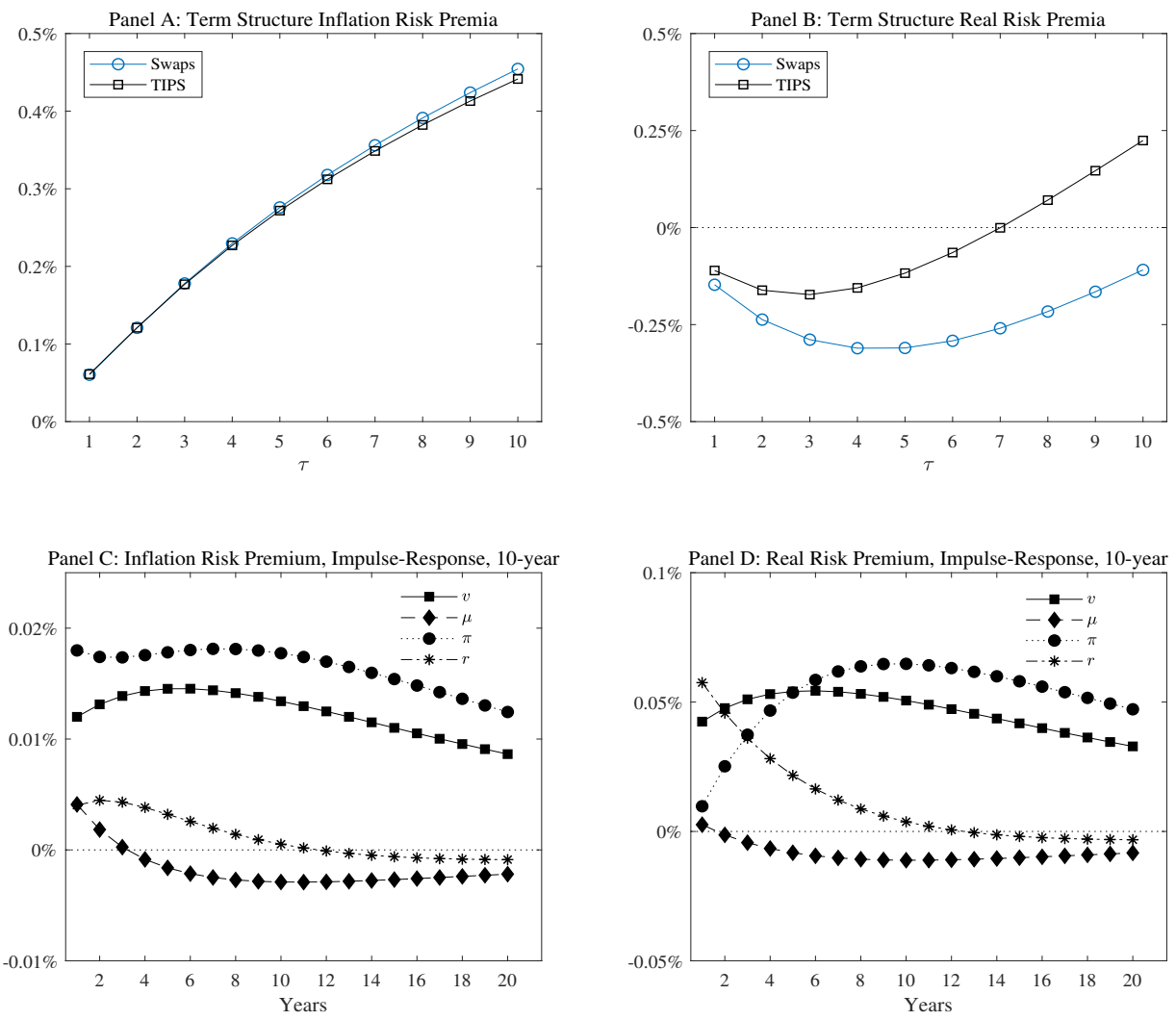
Table A.1

\section{Model-implied factor loadings}

The table reports the model-implied factor loadings (that is, the $B$ coefficients in the affine expressions) for nominal yields, real yields, TIPS, inflation expectations, inflation risk premia, and real risk premia at the 2-year, 5-year, and 10-year maturity. For all series but TIPS, the loadings on the liquidity factor $\ell$ are zero.

\begin{tabular}{|c|c|c|c|c|c|c|c|c|}
\hline \multirow[b]{2}{*}{$\tau$} & \multicolumn{4}{|c|}{ Nominal yields, $Y(\tau)$} & \multicolumn{4}{|c|}{ Real yields, $R(\tau)$} \\
\hline & $v$ & $\mu$ & $\pi$ & $r$ & $v$ & $\mu$ & $\pi$ & $r$ \\
\hline 2 & 5.3086 & 0.0175 & 0.6658 & 0.8324 & 3.6195 & 0.0058 & -0.0576 & 0.8502 \\
\hline 5 & 8.5139 & 0.0042 & 0.6473 & 0.6854 & 5.9000 & -0.0066 & 0.0782 & 0.6984 \\
\hline 10 & 8.4699 & -0.0221 & 0.7093 & 0.4924 & 6.7118 & -0.0301 & 0.3011 & 0.5011 \\
\hline
\end{tabular}

\begin{tabular}{|c|c|c|c|c|c|c|c|c|c|}
\hline & \multicolumn{4}{|c|}{$\operatorname{TIPS}(\tau)$} & & \multicolumn{4}{|c|}{ Expected inflation, $\Pi(\tau)$} \\
\hline$\tau$ & $v$ & $\mu$ & $\pi$ & $r$ & $\ell$ & $v$ & $\mu$ & $\pi$ & $r$ \\
\hline 2 & 4.0368 & 0.0049 & -0.0475 & 0.8512 & 0.9804 & 1.8705 & -0.0026 & 0.7062 & -0.0139 \\
\hline 5 & 6.7252 & -0.0106 & 0.1191 & 0.7007 & 0.9572 & 2.4984 & -0.0206 & 0.5269 & -0.0117 \\
\hline 10 & 7.6871 & -0.0383 & 0.3798 & 0.4997 & 0.9132 & 2.2124 & -0.0324 & 0.3848 & -0.0113 \\
\hline
\end{tabular}

\begin{tabular}{|c|c|c|c|c|c|c|c|c|}
\hline \multirow[b]{2}{*}{$\tau$} & \multicolumn{4}{|c|}{ Inflation risk premium, $\operatorname{IRP}(\tau)$} & \multicolumn{4}{|c|}{ Real risk premium, $\operatorname{RRP}(\tau)$} \\
\hline & $v$ & $\mu$ & $\pi$ & $r$ & $v$ & $\mu$ & $\pi$ & $r$ \\
\hline 2 & 0.1257 & 0.0113 & 0.0286 & -0.0022 & 0.2459 & 0.0065 & -0.1020 & 0.1157 \\
\hline 5 & 0.3285 & 0.0276 & 0.0527 & -0.0001 & 0.7941 & 0.0284 & -0.1243 & 0.1899 \\
\hline 10 & 0.5427 & 0.0328 & 0.0761 & 0.0058 & 1.5938 & 0.0380 & -0.0272 & 0.1950 \\
\hline
\end{tabular}




\section{Figure A.1. Time series of actual and model-implied series}

This figure displays the actual (solid blue line) and model-implied (dash-dot dark line) time series of: the 5-year nominal yield (Panel A); the 5-year TIPS yield (Panel B); the realized volatility of the 5-year nominal yield (Panel C); the implied volatility of the option on the 10-year T-note future. Panels $\mathrm{E}$ and $\mathrm{F}$ display the actual (solid blue line) median professional forecasts for 1-year ahead Inflation (GDP deflator) and real GDP growth, and the model-implied (dash-dot dark line) inflation and growth expectations.
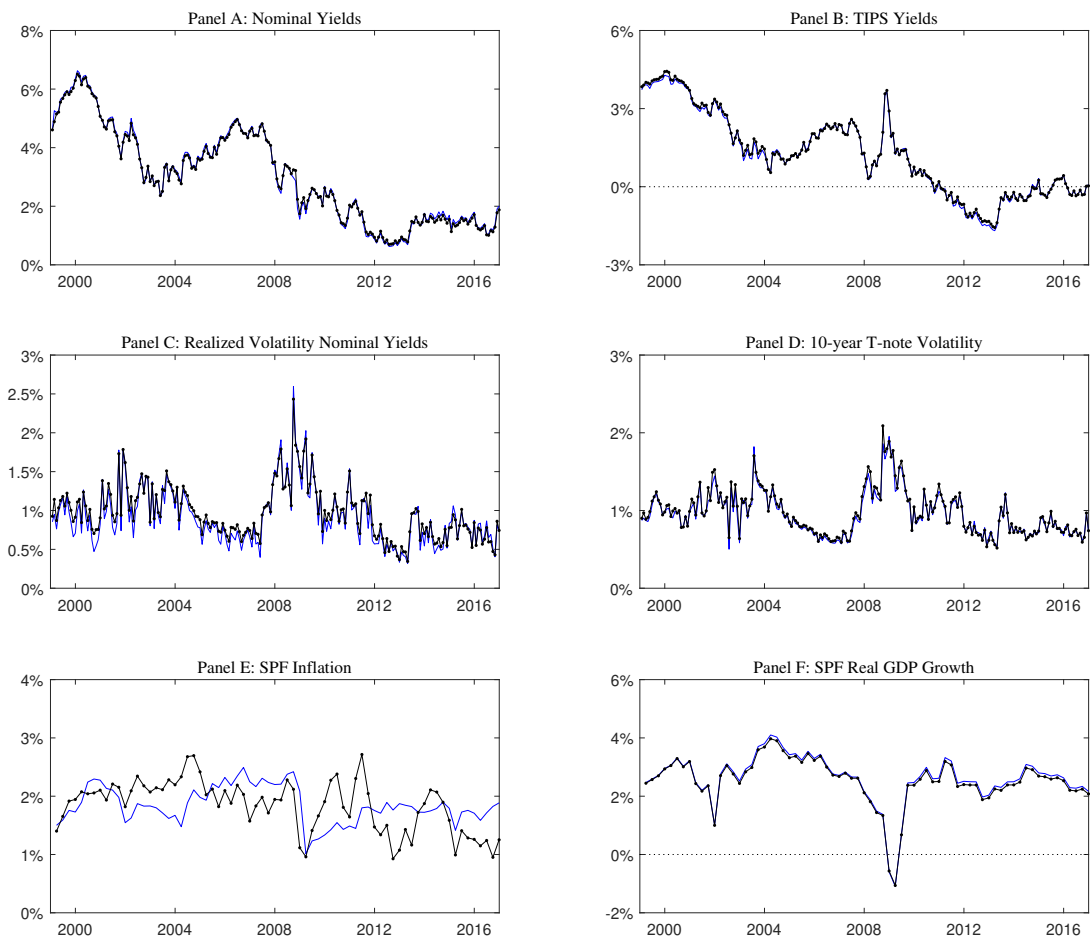